\title{
Research on Collaborative Governance of Smart Government Based on Blockchain Technology: An Evolutionary Approach
}

\author{
Shaonan Shan $\mathbb{D}^{1,2}$ Xia Duan $\mathbb{D}^{1},{ }^{1}$ Ying Zhang, ${ }^{3}$ Ting Ting Zhang, ${ }^{4}$ and Hui Li ${ }^{5}$ \\ ${ }^{1}$ School of Urban Economics and Public Administration, Capital University of Economics and Business, Beijing 100070, China \\ ${ }^{2}$ School of Business Management, Liaoning Vocation Technical College of Modern Service, Shenyang 110164, Liaoning, China \\ ${ }^{3}$ School of Business Administration, Henan University of Animal Husbandry and Economy, Zhengzhou 450044, Henan, China \\ ${ }^{4}$ School of Public Finance and Taxation, Capital University of Economics and Business, Beijing 100070, China \\ ${ }^{5}$ School of Management, Guangxi University for Nationalities, Nanning 530006, Guangxi, China \\ Correspondence should be addressed to Xia Duan; duanxia0517@sina.com
}

Received 13 November 2020; Revised 2 January 2021; Accepted 24 January 2021; Published 16 February 2021

Academic Editor: Zengqiang Chen

Copyright $\odot 2021$ Shaonan Shan et al. This is an open access article distributed under the Creative Commons Attribution License, which permits unrestricted use, distribution, and reproduction in any medium, provided the original work is properly cited.

\begin{abstract}
Smart government is an important means of optimizing government management, improving the government decision-making capacity, and pushing forward the public service. When the smart government process applies, the dire straits of collaborative governance among the different participants could not be ignored usually caused by maximizing their profits. Based on the current research, this paper introduces the blockchain technology into the smart government system and establishes a smart government platform architecture. Meanwhile, to analyse the evolutionary and stable strategies of the three parties under the blockchain technology, the evolutionary game model including functional departments, local governments, and end users as the main players is established on account of the bounded rationality. By examining the "blockchain + government service" in Beijing with the systemic dynamics theory, this paper changes the influencing factors simulated by changing the parameter assignment, to determine the evolutionary stable equilibrium under different external conditions. The results show that local government supervision plays a leading role in the process of collaborative governance of smart government based on blockchain technology; meanwhile, effective cost control is a key factor affecting the evolutionary stability strategy (ESS). Besides, the "decentralized" structure, "distrust" architecture, and "precision" mechanism of the blockchain are verified for the effect of the evolution process. Among them, precision service and flat management improve the possibility of collaborative governance, but the impact of the trust mechanism is not obvious. Therefore, the collaborative governance model of smart government based on blockchain technology is loaded with far-reaching significance for promoting the modernization of China's governance capacity and governance system.
\end{abstract}

\section{Introduction}

As science and technology are leaping forward and the concept of modern governance is advancing, government departments should take the strategic measure of optimizing their decision-making ability and elevate their social service level by exploiting emerging technological means to develop smart government affairs. Since 2008, IBM proposed "smart Earth" initially [1]. The concept of using novel technological means to assist government governance decision-making and optimize public service capacity has been rapidly recognized worldwide, gradually forging a global upsurge of pursuing and delving into the development of smart government affairs. As suggested from the 2018 UN survey report [2], in 2018, there were 36 leading e-government developing nations (very high EGDI, greater than 0.75 ). To be specific, there were 26 European nations, taking up $72 \%$, and 5 nations in Asia, accounting for 14\%; there were two nations in the Americas and Oceania, taking up 14\%, and one country in Africa, occupying 3\% (see Figure 1). According to the survey results, there are three important dimensions in the e-government development index (EGDI), i.e., the online service index (OSI), the data communication infrastructure index (TII), and the human 


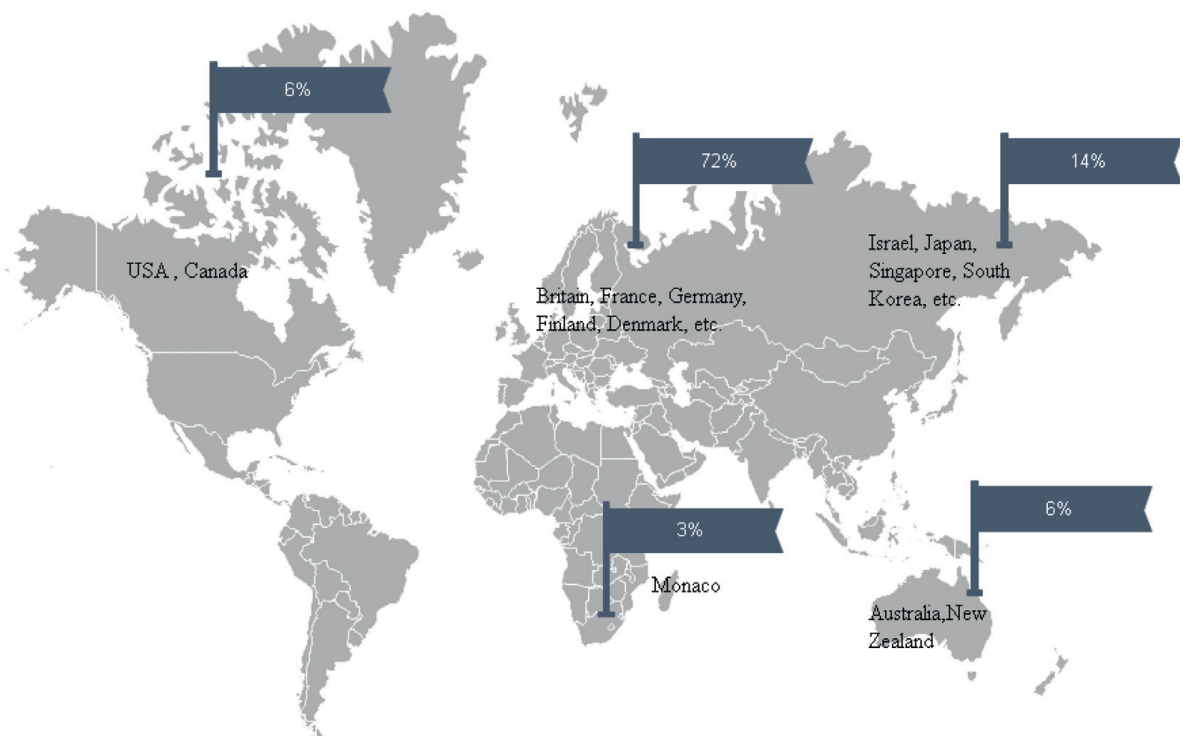

FIgURE 1: The distribution map of the world's leading e-government development nations and regions in 2018.

resources index (HCI). Nations stressed the development of government affairs information, and each index was improved significantly in 2018, thereby boosting rapid development of smart government governance (see Figure 2).

Over the past few years, the Chinese government has repeatedly proposed to deepen "Internet+government services," streamline government processes, improve service efficiency, and save people's processing time and other policies, as an attempt to ensure the steady implementation of the strategy of "promoting the modernization of national governance systems and governance capabilities." Smart government complies with the development of the times. By improving the scientific decision-making capacity of the government, reducing the red tape of business handling, arousing the initiative of diversified governance, and building a novel model of accurate governance and multiparty coordination, the production and life of enterprises and the public will be ensured to be optimized and convenient. However, the implementing effect of smart government is hindered by the high cost of platform construction [3], system security risks [4], as well as the ambiguity of the rights and responsibilities of governance bodies [5]. As suggested by the Internet Service Capability Development Report of Local Governments in China (2019) [6], 217 prefecture-level administrative regions in China have rolled out Internet government service projects. To be specific, 14 local governments exhibited prominent Internet service response capability. However, 117 prefecture-level cities remained, and Internet government services continue to progress steadily and develop urgently. Thus, under the existing obstacles, drawing on national policy calls and guidance only cannot further boost the steady progress of smart government affairs.

Numerous factors are restricting the implementation of smart government affairs (e.g., "information island" and "data chimney" [7]; system loopholes and privacy disclosure [8]; and risks and benefits of multiple parties and uneven



Figure 2: Breakdown of EGDI indices comparing data from 2014, 2016, and 2018.

distribution of rights and obligations [9]). To address such a restriction, the government employs data collection, data interoperability, and incentives for business collaboration and subsequently reshapes government service processes and other public management methods to boost itself to achieve informatization [10]. For implementing effects, good effects have been achieved, among which big data technology driving [11] and cross-department information sharing [12] exert the critical effects. Besides, different performance assessment systems and reward and punishment mechanisms help tackle down the bottleneck problem when promoting smart government affairs. For instance, the construction of the intelligent government information ecological assessment system, the influencing mechanism, and functional relationship among the driving force, the pressure, and the state and response factors are clarified to enhance the comprehensive serviceability of smart government affairs [13]. Given the service quality and satisfaction of smart government [12], the assessment index [14] for enhancing the administrative performance of the local government is 
set to promote the steady development of smart government. The operation mechanism of "Achievement safety area" is exploited to encourage local governments to implement continuous "innovative practice," and then it is applied for promoting smart government projects [15]. The world is developing rapidly in emerging technologies in information technology, whereas the technology is slightly inferior in smart government projects construction. Accordingly, emerging technologies should be organically combined with the smart government to form a novel type of wisdom characterized by the development of the times. The government affairs model is imperative, and blockchain technology presents novel insights into addressing the bottleneck problems facing smart government affairs.

The core concept and significance of blockchain technology refer to data association [16] and a novel distributed infrastructure and computing paradigm of epoch-making significance [17]. As highlighted by the World Economic Forum in Davos, by 2023, 10\% of the global GDP will be stored in blockchain or blockchain-related technologies, and the blockchain technology will be extensively exploited by government agencies [18]. Moreover, China has identified blockchain as one of the nation's vital strategic frontier information technologies [19], an important support for building a digital China [20]. Blockchain technology is currently involved in numerous fields of public affairs management (e.g., public services, social security, public information and communication, artificial intelligence, and logistics supply chain). The premise for the application of blockchain technology in smart government affairs indicates that it has economic profit space and is capable of fitting the expected returns and returns of social capital to achieve the maximum benefit. Thus, government departments and platform users are both partners and rational groups pursuing the maximization of their respective interests when participating in the operation of smart government affairs, complying consistent with the evolutionary game theory in economics. Subsequently, it is feasible to use evolutionary game theory to analyse the blockchain technology to enable intelligent government collaborative governance [21].

This study answers the following key questions:

(1) Whether blockchain technology can promote collaborative governance among smart government participants. If so, how the smart government system applies blockchain technology requires analysis. Subsequently, for the stability of collaborative governance and the possibility of the occurrence of ideal events, the factors should be elucidated.

(2) If blockchain technology enables collaborative governance of smart government affairs, the following problems will arise.

(3) How does blockchain technology impact the development of collaborative governance of smart government?

(4) Under "blockchain + smart government," how should the participants select the optimal strategy, i.e., active collaboration or maintaining the status quo?
(5) How to optimize the smart government collaborative governance model with the empowerment of blockchain technology?

The rest of this study is organized as follows. In Section 2, a comprehensive review of the relevant literature on blockchain technology and smart government is presented. In Section 3, the characteristics of blockchain technology and smart government are combined to build a revised version of smart government platform architecture with blockchain technology, building a theoretical framework for relevant research. In Section 4, the evolutionary game model is adopted to analyse how to achieve the game evolution and stability strategy of functional departments, local governments, and end users, as well as how to achieve a tripartite cooperation equilibrium. In Section 5, the case of "blockchain + government services" in Beijing is analysed, system dynamics theory is combined to change the assignment of external variables, and the influence mechanism of the three parties is simulated actively using blockchain technology to deepen the collaborative governance of smart government affairs. In Section 6, the research findings are summarized and corresponding policies are formulated.

\section{Literature Review}

Existing studies on the application of blockchain technology in government affairs service primarily focus on the macroscopic and microscopic levels. At the macroscopic level, domestic and foreign scholars analysed the technological advantages of blockchain application in government services and studied each policy of "blockchain + government services." When comparing the application of blockchain to government service policies in a range of nations, the researchers indicated the advantages brought by advanced technology, analysed the possible defects and proposed the corresponding suggestions [22-24]. Local governments can refer to the mentioned studies in their decision-making to assess the possibility of applying blockchain technology to government services in their regions. At the microscopic level, existing studies primarily assessed security concerns in governmental use of blockchain technology [25], the application of blockchain to e-Residency [26], blockchain and big data combine to elevate the level of urban governance and social information [12, 27], financial network governance and freight assessment [28-30], and smart city governance $[31,32]$. As a research hotspot in the multidisciplinary field, such a type of research covers most aspects of the development of "blockchain + government service," whereas it lacks systematic and dynamic research methods.

As demonstrated above, there is little guidance concerning the dynamic evolution of behaviour strategies between government service participants under the blockchain technology (i.e., policies and measures aimed at facilitating collaborative behaviours among participants). Such a type research combines macro and micro levels and considers government service participants' characteristics. Kallstrom and Mauro analysed a process of citizens' and stakeholders' 
engagement promoted by a local authority to codesign the city vision with multiple actors (e.g., politicians, public managers, consultants, citizens, and other external stakeholders). They consider that the players in the game are completely rational, and the policy is statically implemented [33]. However, behavioural psychology reveals that decision-makers are short-sighted and heterogeneous, and all parties are inclined to bounded rationality [34]. In practice, China's e-government service development remains in the initial stage for the immaturity in core technologies, imperfect infrastructure, and cognition of participants [35]. In online government services, local governments, functional departments, and end users interact dynamically. The three parties should share their own experiences and modify their strategies repeatedly by keeping abreast with external environment changes. Accordingly, the premise of bounded rationality and dynamic evolution of the evolutionary game theory comparatively abides by the behaviour rules and decision-making characteristics of local governments, functional departments, and end users. For instance, Zhang and $\mathrm{Li}$ studied multiagent collaborative governance for targeted poverty alleviation based on the evolutionary game analysis framework [36]. They built a three-agent evolutionary game model of local governments, social organizations, and poor groups, and they investigated the impact of their behaviour decisions on multiagent cooperative governance of targeted poverty alleviation. However, the discussion on the stability of the cooperative governance system was ignored. Zhang et al. [37], Xu et al. [38], and Chen et al. [39] initially carried out evolutionary game modelling to study the coordinated governance of haze by heterogeneous governments, heavy metal pollution control in soil, and the relationship among government, the enterprise, and the public in environmental governance from the perspective of stakeholders' strategy selection. Subsequently, they verified game models and theoretical results based on numerical examples, case studies, and empirical analysis, respectively. Wan and Qie [40] and Hou and Li [41] investigated the tripartite game between the government smart financial poverty alleviation ecosystem and the collaborative innovation system of IoT. As impacted by the different research perspectives and points of departure, the existing studies failed to consider the optimization effect of emerging technologies (e.g., artificial intelligence, big data, cloud computing, and blockchain) on smart platform systems, as well as the interactive decision-making behaviour and evolutionary stable state of intelligent platform system participants under the novel technology. Thus, the realization of interagent cooperative behaviour and the impact of external factors on interagent cooperative behaviour are largely ignored. In practice, the lack of theoretical research causes weak guidance. To effectively promote the intelligent platform system empowered by emerging technology and form the situation of multisubject collaborative participation, further research is required in China.

As the current smart platform systems are plagued by system vulnerabilities, privacy disclosure, trust crisis, and others, a modified smart government platform architecture is developed here under the blockchain technology and uses the replicator dynamic analysis method to model the decision-making of the three main participants of smart government. This study explores how the dynamic interaction between local governments, functional departments, and end users impacts the behaviour of participants, while determining the main factors of the multiagent collaborative governance in the complex system of "blockchain + smart government," which can effectively guide decision-making of local governments, functional departments, and end users.

The differences between this study and the relevant literature are presented below. This study (1) attempts to explore the architecture of a smart government platform with blockchain technology, (2) analyses the major stakeholders under this framework and considers the evolutionary game situation of stakeholders under the condition of bounded rationality, (3) obtains the stable state, and (4) draws the key factors for the collaborative governance of smart government with blockchain technology.

\section{Collaborative Governance Model of Smart Government with Blockchain Technology}

3.1. Basic Ideas. The smart government refers to the resource integration and system integration between government internal business systems and external (parallel/subordinate) functional departments. It seeks to achieve the reprovisioning and integration of government processes and resources to provide convenient, high-quality, and low-cost one-stop services to the public and enterprises, to link the cross-functional departments and system integration to complete approval in parallel, to carry out the transparent, clean, and efficient operation of the online administrative management system, and to build a through service bus that comprises process engine management, intranet portal, extranet business, and thematic database and derivative central database [42]. However, the "blockchain technologybased collaborative governance model for smart government affairs" indicates that to solve the obstacles and difficulties facing existing smart government affairs, the original smart government affairs technical framework is revised by introducing blockchain technology (see Figure 3). Blockchain technology features (e.g., "decentralized" structure, "detrust" structure, and "precision" mechanism) can effectively tackle down various obstacles facing smart government affairs. This architecture corresponds to the blockchain 6-tier structure to the ISO7-tier structure and modifies it. Given relational data (e.g., Oracle) and various algorithm technologies, the consensus layer and the incentive layer are the core service layers of the blockchain, overlaying end user service business function scenarios to form an efficient, safe, and credible government service system. The tamper-proof and asymmetric encryption technology of blockchain can ensure the security and privacy of data storage. As ensured by peer-to-peer equality protocol and peer-to-peer transmission technology, the information in the system can be exchanged, recognized, and transmitted in an unimpeded manner. Various efficient algorithms to achieve interaction process fast, short response time, and strong fault tolerance 




FIgURE 3: Modified smart government platform architecture with blockchain technology.

are conducive to value the mutual recognition and behaviour consensus. Technology features (e.g., decentralization, traceability, editability, security, and reliability) ensure that multiple governance subjects can forge a multiple collaborative governance situation [43]. Accordingly, this model significantly improves the security, convenience, coordination, and intelligence of the original system, thereby increasing social capital and economic benefits.

3.2. Stakeholder Analysis. For all stakeholders, in the collaborative governance model of smart government with blockchain technology, the collaborative governance bodies involved include functional departments, local governments, and end users. The starting point of each subject is different, so its basic idea of participating in smart government affairs is based on different decision-making behaviours attributed to different positions and perspectives of all parties in the process of platform operation. According to Figure 4, from the perspective of the goals of collaborative governance entities, the goals of local government departments, functional gates, and end users are identical. They overall use blockchain technology to obtain better smart government operations and use effects, and they achieve more a considerable number of total benefits. This also complies with the behaviour of "rational people" from the perspective of economics, i.e., the pursuit of self-interest maximization. For each subject, the model refers to a Pareto improvement process. The subject's focus is different because its goal is to maximize self-interests. To be specific, local governments are concerned with whether the benefits of social public services can be maximized, functional departments stress whether their business service levels and performance gains are maximized, and end users are more 


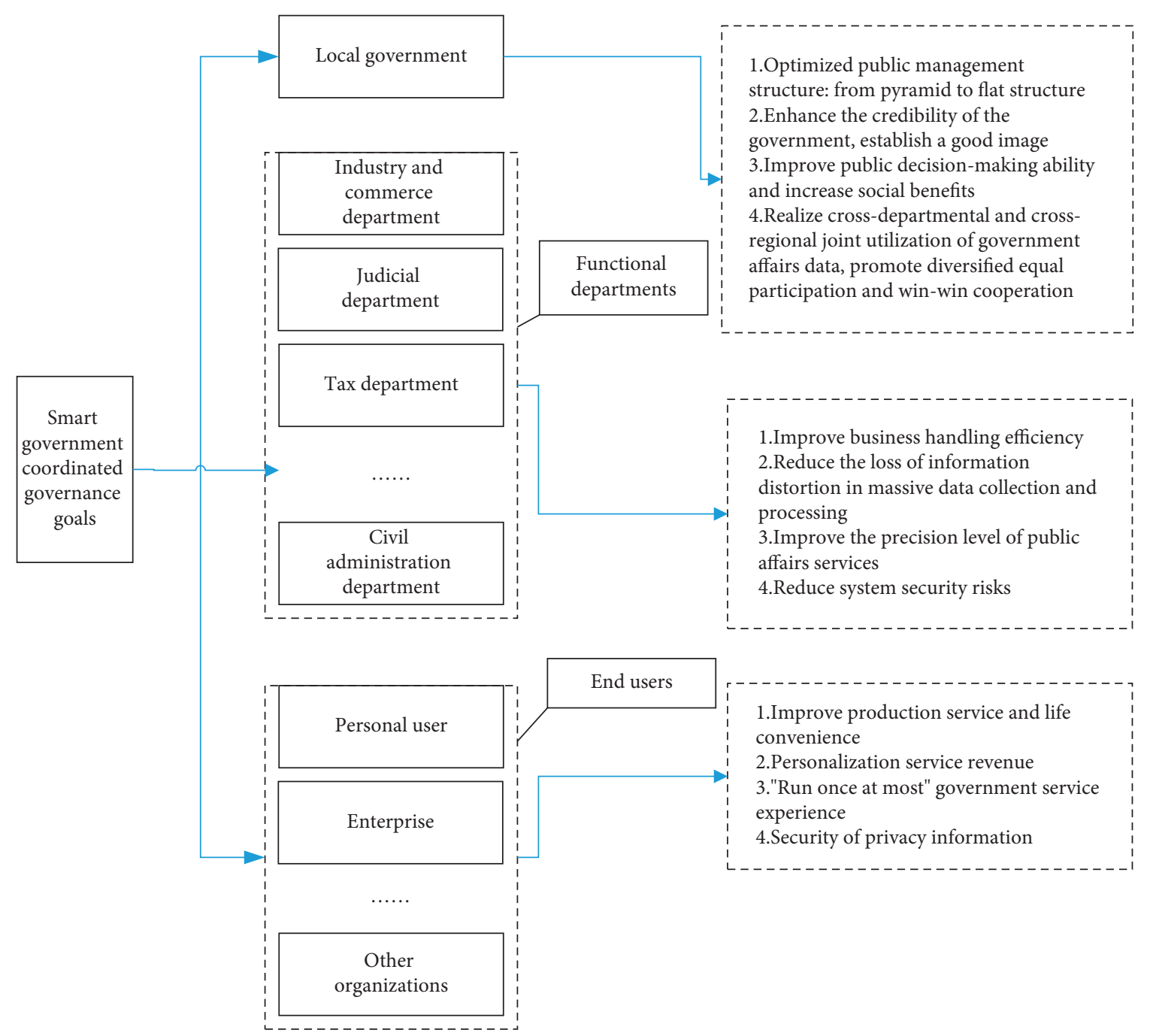

FIgURE 4: The goal of each stakeholder in the smart government collaborative governance model with blockchain technology.

concerned with maximizing the overall benefits (e.g., ease of use, security, and satisfaction). However, through continuous adjustment and optimization under the long-term contractual relationship of the parties, the respective advantages can be exploited to lastly achieve the win-win cooperation of all parties and achieve the maximization of self-interest under the smart government coordinated governance with blockchain technology.

3.3. Profit Mechanism. In the application of blockchain technology for constructing smart government affairs projects, only when the total revenue of system operation is greater than the total cost of construction can the project be implemented. Thus, to ensure the smooth operation and promotion of blockchain-based smart government projects, the future direct income and potential income should be balanced and coordinated after the operation to ensure the realization of "Pareto optimality" between the incomes of all parties participating in collaborative governance, as well as mobilize the enthusiasm of all subjects maximally. Combined with the advantages of blockchain technology, the present study makes an in-depth analysis of the economic benefits in the collaborative governance model of smart government based on blockchain technology as shown in Figure 5.

\subsection{Collaborative Governance Organizational Structure.} Though in the collaborative governance model of smart government with blockchain technology, the stakeholders involved mainly include functional departments, local governments, and end users. However, the operation of smart government projects is highly technical, which continues to operate, exhibits strong externalities, and involves numerous participants; the relationship between them is very sophisticated as well, covering third-party companies (e.g., system development companies, operation and maintenance outsourcing parties, and blockchain technology providers), as well as nongovernmental organizations (e.g., chambers of commerce and social groups). Based on the existing research results, the present study analyses and designs the operation organization structure of the smart government collaborative governance model with blockchain technology (see Figure 6). 

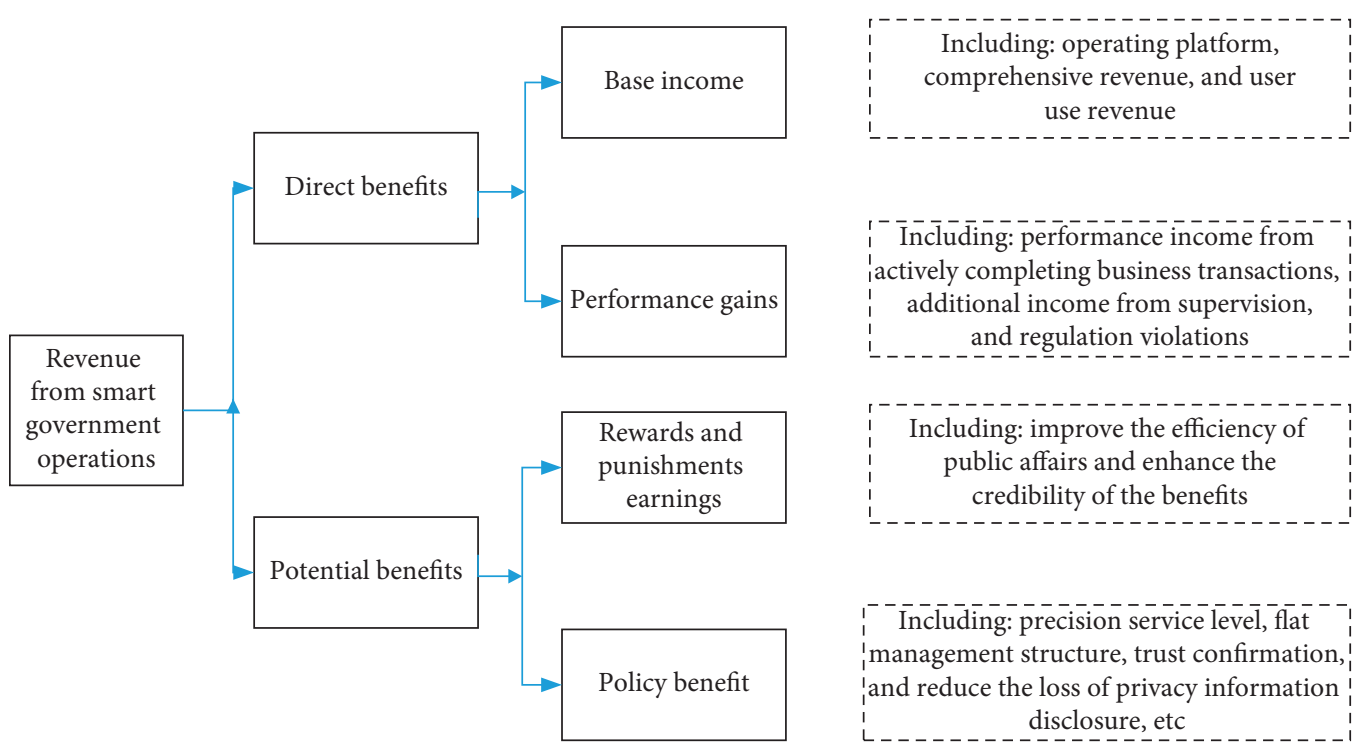

FIGURE 5: Analysis of the operational income of smart government projects based on blockchain technology.



FIGURE 6: Framework diagram of the collaborative governance organization structure of smart government projects with blockchain technology.

\section{Assumptions and Construction of the Evolutionary Game Model}

4.1. Basic Assumptions. This study assumes that the strategies of functional departments are Positive, Negative $\}$. The strategies of local government are $\{$ Strict supervision, Loose supervision\}, while those of end users are $\{$ Use, Nonuse\}. $x$, $y$, and $z$, respectively, denote the probability of functional departments' choice of blockchain + government services technology, local government supervision, and end users' use smart government platform. In correspondence, 1-x, 1-y, and $1-z$ represent that the probability that functional 
departments do not choose "blockchain + government services" technology, that the local government does loose supervision, and that end users do not use smart government platform, respectively.

$\mathrm{C}_{4}$ refers to the cost paid by the functional departments when they do not choose blockchain + government services technology strategies. $I_{2}$ and $\beta S_{2}$, respectively, represent the benefit increase that the functional departments can obtain by drawing upon blockchain + government services technology. $C_{3}$ represents the cost of functional departments when they comply with blockchain + government services technology strategy.

$C_{2}$ denotes cost paid by the local government when they do not choose strict supervision. $C_{1}$ represents cost paid by the local government when they choose strict supervision. Under functional departments choosing negative strategy, $A_{1}$ and $\alpha S_{1}$, respectively, represent the benefit increase of the government when the government follows the "strict supervision" strategies. Under end users choosing use strategy, $P_{1}$ represent punishments paid by the government when the government adopts the "Loose supervision" strategy.

$C_{5}$ represents cost paid by the end users when they do not exploit smart government platform. $I_{3}$ denotes the utility increase of the end users when they follow smart government platform. When local governments select "Loose supervision" strategies, the end users can suffer $P_{1}$ from a loss of privacy.

Under blockchain + government services technology, the coefficient of improving the precision service level for the functional departments is $\beta$ when they follow positive strategies. The coefficient of optimizing the flat management efficiency of the public management structure for the local government is $\alpha$ when they select strict supervision strategies. The coefficient of empowering trust for the end users is $\gamma$ when they comply with strategies. According to the actual situation, we suppose that $0 \leq \alpha, \beta, \gamma \leq 1$. The corresponding parameters are listed in Table 1.

4.2. Model Construction. Based on the mentioned model assumptions, the present study builds a three-party payoff matrix of functional departments, local government, and end users. The first, second, and third functions represent the functional departments' payoff, the payoff of local government, and the payoff of end users, respectively. The specific form of the payoff matrix of each party is listed in Table 2.

\subsubsection{The Construction of the Expected Return Function of All Parties}

(1) Revenue Analysis of Functional Departments. According to the return matrix listed in Table 2, the benefits of positive strategy and negative strategy employed by functional departments are the following equations, respectively:

$$
\begin{aligned}
E_{x}= & y z\left(I_{2}-C_{3}+\beta S_{2}\right)+(1-y) z\left(I_{2}-C_{3}-P_{2}\right) \\
& +y(1-z)\left(I_{2}-C_{3}\right)+(1-y)(1-z)\left(I_{2}-C_{3}-P_{2}\right) \\
= & I_{2}-C_{3}+(y-1) P_{2}+y z \beta S_{2}, \\
E_{1-x}= & y z\left(I_{2}-C_{4}-P_{4}\right)+(1-y) z\left(I_{2}-C_{4}\right) \\
& +y(1-z)\left(I_{2}-C_{4}-P_{4}\right)+(1-y)(1-z)\left(I_{2}-C_{4}\right) \\
= & I_{2}-C_{4}-y P_{4} .
\end{aligned}
$$

Average revenue of functional department is as follows:

$$
\bar{E}=x E_{x}+(1-x) E_{1-x} .
$$

(2) Revenue Analysis of Local Government. The fitness of local government that adopt strict supervision strategy and loose supervision strategy is written as follows:

$$
\begin{aligned}
U_{y}= & x z\left(I_{1}-C_{1}+\alpha S_{1}\right)+x(1-z)\left(I_{1}-C_{2}\right) \\
& +z(1-x)\left(I_{1}-C_{1}+A_{1}\right) \\
& +(1-x)(1-z)\left(I_{1}-C_{1}+A_{1}\right), \\
U_{1-y}= & x z\left(I_{1}-C_{2}-P_{1}\right)+x(1-z)\left(I_{2}-C_{4}\right) \\
& +z(1-x)\left(I_{2}-C_{2}-P_{1}\right) \\
& +(1-x)(1-z)\left(I_{2}-C_{2}\right) \\
= & I_{1}-C_{2}-z P_{1} .
\end{aligned}
$$

Average revenue of local government is as follows:

$$
\bar{U}=y U_{y}+(1-y) U_{1-y} .
$$

(3) Revenue Analysis of End Users. The fitness of end users that adopt use strategy and nonuse strategy is expressed as follows:

$$
\begin{aligned}
V_{z}= & x y\left(I_{3}-\gamma S_{3}\right)+x(1-y)\left(I_{3}-P_{3}\right)+y(1-x) I_{3} \\
& +(1-x)(1-z)\left(I_{3}-P_{3}\right)=I_{3}+(y-1) P_{3}+x y \gamma S_{3}, \\
V_{1-z}= & x y\left(-C_{5}\right)+x(1-y)\left(-C_{5}\right)+y(1-x)\left(-C_{5}\right) \\
& +(1-x)(1-y)\left(-C_{5}\right)=-C_{5} .
\end{aligned}
$$

Average revenue of end user is as follows:

$$
\bar{V}=z V_{z}+(1-z) V_{1-z} .
$$

\subsubsection{The Replication Dynamic Equation of Three-Party Evolutionary Game \\ (1) Replication Dynamic Equation of Functional Depart- ments. According to equations (1)-(3), the replication dy- namic equation of functional departments adopting the "Positive" strategy is defined as follows:}


TABLE 1: Main parameters and their meaning.

\begin{tabular}{lcc}
\hline Game player & Sign & Variable \\
\hline$I_{2}$ & Performance benefits of smart government platform business processing \\
Functional & $C_{3}$ & Actively use blockchain technology to optimize the cost of smart government business processing \\
department & $P_{4}$ & When not in use blockchain technology huge amounts of data collect processing information distortion \\
expenditure & Using blockchain technology to improve the precision service level of functional departments
\end{tabular}

Table 2: Payment matrix of functional departments, local governments, and end users.

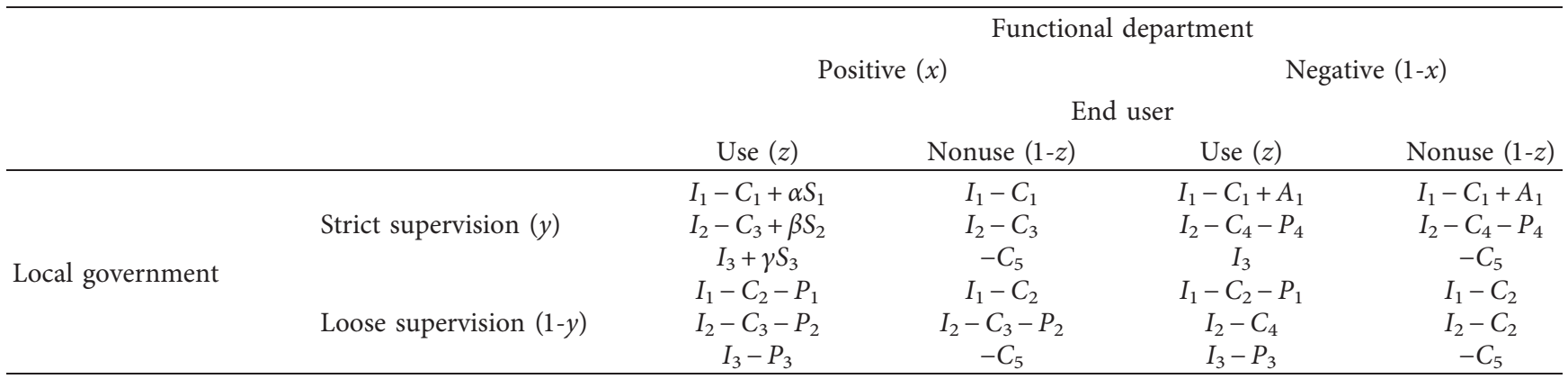

$$
\begin{aligned}
F(x) & =\frac{\mathrm{d} x}{\mathrm{~d} t}=x\left(E_{x}-\bar{E}\right)=x(1-x)\left(E_{x}-E_{1-x}\right) \\
& =x(1-x)\left(C_{4}-C_{3}+(y-1) P_{2}+y P_{4}+y z \beta S_{2}\right) .
\end{aligned}
$$

(2) Replication Dynamic Equation of Local Government. According to equations (4)-(6), the replication dynamic equation of "strict supervision" strategy adopted by local government is as follows:

$$
\begin{aligned}
F(y) & =\frac{\mathrm{d} y}{\mathrm{~d} t}=y\left(U_{y}-\bar{U}\right)=y(1-y)\left(U_{y}-U_{1-y}\right) \\
& =y(1-y)\left(C_{2}-C_{1}+A_{1}-x A_{1}+z P_{1}+x z \alpha S_{1}\right) .
\end{aligned}
$$

(3) Replication Dynamic Equation of End Users. According to equations (7)-(9), the replication dynamic equation of "Use" strategy adopted by end user is expressed as follows:

$$
\begin{aligned}
F(z) & =\frac{\mathrm{d} z}{\mathrm{~d} t}=z\left(V_{z}-V_{1-z}\right) \\
& =z(1-z)\left(I_{3}+C_{5}-(1-y) P_{3}+x y \gamma S_{3}\right) .
\end{aligned}
$$

\subsection{Model Analysis}

4.3.1. Evolution Path and Stability Analysis of Three-Party Agent Strategy. In accordance with the stability theorem of differential equation, the stable point of the replication dynamic equation should be located at the zero point where the first derivative is less than zero, i.e., it should be written as follows:

$$
\frac{\mathrm{d}(F(x))}{\mathrm{d} x}<0 \mid F(x)=0, \quad x \in[0,1] .
$$


Subsequently, the evolution and stability strategies of the three main agents of functional departments, local governments, and end users can be discussed.

(1) The Asymptotic Stability Analysis of Functional Departments. The first partial derivative of the replication dynamic equation with positive strategy for $x$ can be determined by equation (10):

$$
\frac{\partial F(x)}{\partial x}=(1-2 x)\left(C_{4}-C_{3}+(y-1) P_{2}+y P_{4}+y z \beta S_{2}\right) .
$$

If we set

$$
\Pi_{x}=\left(C_{4}-C_{3}+(y-1) P_{2}+y P_{4}+y z \beta S_{2}\right),
$$

and from $\Pi_{x}=0$, the following equation is yielded:

$$
\lambda_{y}=\frac{P_{2}+C_{3}-C_{4}}{P_{2}+P_{4}+z \beta S_{2}} .
$$

Then, we have Conclusion 1. enun_Conclusion_1

Conclusion 1. When $\Pi_{x}>0$, the positive strategy of functional departments is the evolutionary stability strategy; when $\Pi_{x}<0$, the negative strategy of the functional departments is an evolutionary stability strategy. Furthermore, the probability of $x$ increases, while the probability of $y$ and $z$ is elevated.

Theorem 1. $\Pi_{x}=0$ is the dividing line of the stable state of functional departments (see Figure $7(a)$ ). According to the stability theorem of the differential equation, when $\Pi_{x}>0$ has $F_{(x)}{ }^{\prime}>0, F_{(x)}{ }^{\prime}<0$, it indicates the stable state of positive strategy of functional departments, while the negative strategy is unstable (see Figure 7(b)). Likewise, when $\Pi_{x}<0$ has $F_{(x)}{ }^{\prime}(0)<0, F_{(x)}^{\prime}(1)>0$, it indicates that the negative strategy of the functional departments is in a stable state, while the positive strategy is unstable (see Figure $7($ c)).

When $y>\lambda_{y},\left.(F(x) / \mathrm{d} x)\right|_{x=1<0}$, indicating that the evolution stable strategy of the functional departments is $x=1$. In other words, functional departments are inclined to follow a positive strategy under the probability of $y$ higher than $\lambda_{y}$.

When $y<\lambda_{y},\left.(F(x) / \mathrm{d} x)\right|_{x=0<0}$, indicating that the evolution stable strategy of the functional departments is $x=0$. In other words, functional departments tend to select a negative strategy when the probability of $y$ is lower than $\lambda_{y}$. Likewise, we can prove the relationship between $z$ and $x$.

As revealed from the results, the decision-making behaviour of functional departments is affected by numerous factors. According to the formula, the positive decision $(x)$ of functional departments increases with the increase in local governments' strict supervision strategy $(y)$ and end user use strategy $(z)$. Besides, the smaller the difference between the cost expenditure of optimizing smart government business by positively using blockchain technology and the cost expenditure of negatively using blockchain technology, the higher the distortion loss of mass data collection and processing attributed to not using blockchain technology, and the higher the system security problem and the precision service income brought by blockchain technology when local governments are lax in supervision, the higher the possibility for functional departments will choose the positive strategy.

(2) The Asymptotic Stability Analysis of Local Government. The first partial derivative of the replication dynamic equation with strict supervision strategy for $y$ can be obtained according to equation (11):

$$
\frac{\partial F(y)}{\partial y}=(1-2 y)\left(C_{2}-C_{1}+A_{1}-x A_{1}+z P_{1}+x z \alpha S_{1}\right) \text {. }
$$

If

$$
\Pi_{y}=C_{2}-C_{1}+A_{1}-x A_{1}+z P_{1}+z x \alpha S_{1},
$$

and from $\Pi_{y}=0$, the following equation is yielded:

$$
\lambda_{x}=\frac{C_{1}-C_{2}-A_{1}-z P_{1}}{z \alpha S_{1}-A_{1}} .
$$

Then, we have Conclusion 2. enun_Conclusion_2

Conclusion 2. When $\Pi_{y}>0$, the strict supervision strategy of local government is the evolutionary stability strategy; when $\Pi_{y}<0$, the negative strategy of the functional departments is an evolutionary stability strategy. Moreover, the probability of $y$ increases while the probability of $x$ and $z$ is elevated.

Theorem 2. $\Pi_{y}=0$ is the boundary line of the stable state of local government (see Figure 8(a)). According to the stability theorem of the differential equation, when $\Pi_{y}>0$ has $F_{(y)}^{\prime}(0)>0, F_{(y)}^{\prime}(1)<0$, it indicates that the local government is in a stable state when strict supervision strategy is adopted, while the loose supervision strategy is unstable (see Figure $8(b)$ ). Likewise, when $\Pi_{y}<0$ has $F_{(y)}^{\prime}(0)<0, F_{(y)}^{\prime}(1)>0$, this indicates that local government is in a stable state when it choose loose supervision strategy, while strict supervision strategy is unstable (see Figure 8(c)).

When $x>\left.\lambda_{x}(\mathrm{~d} F(y) / \mathrm{d} y)\right|_{y=1<0}$, indicating that the evolution stable strategy of the local government is $y=1$. In other words, local government tends to select a strict supervision strategy when the probability of $y$ is higher than $\lambda_{x}$.

When $x<\lambda_{x},\left.\quad(\mathrm{~d} F(y) / \mathrm{d} y)\right|_{y=0<0}$, indicating that the evolution stable strategy of the local government is $y=0$. In other words, local government tends to select a loose supervision strategy when the probability of $y$ is lower than $\lambda_{x}$. Likewise, we can prove the relationship between $z$ and $y$.

As revealed from the analysis results, the decisionmaking behaviour of the local government is affected by many factors. The formula shows that the local government's strict supervision $(y)$ and decision-making will increase with the increase in the positive strategy $(x)$ of the functional department and the end user strategy $(z)$. Besides, the smaller the difference between the cost of strict supervision 


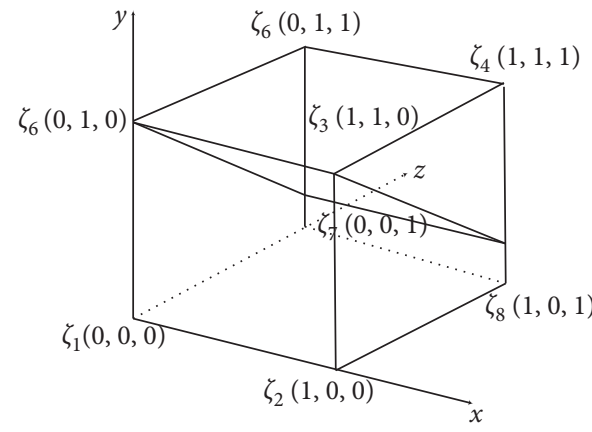

(a)

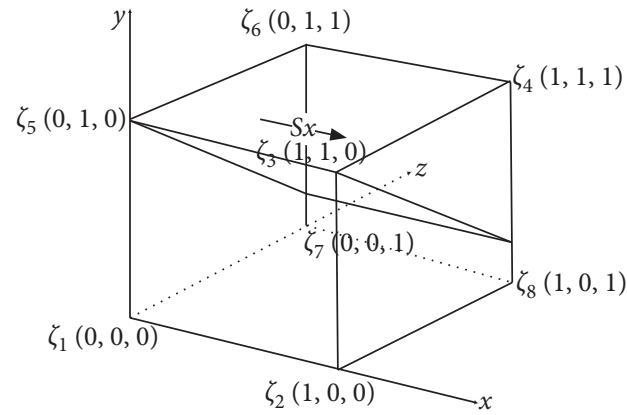

(b)

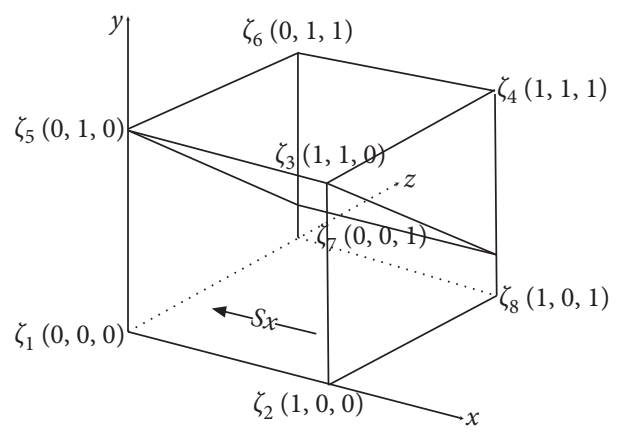

(c)

FIGURE 7: Functional department stability evolution phase diagram.



(a)



(b)

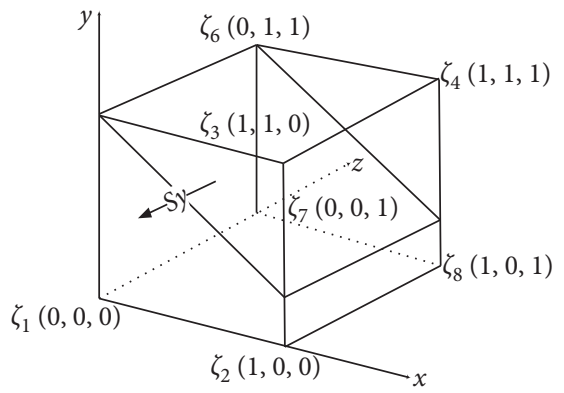

(c)

Figure 8: Phase diagram of local government stability evolution.

by local governments and the cost of lax supervision, the greater the extra benefit from the irregularities of functional departments under strict supervision. The risk of data security attributed to government neglect of supervision damages the credibility of the government and the increase of the income from the flat management of functional departments actively using blockchain technology to optimize the public management structure, which will directly affect 
the improvement of the willingness of local governments to make final strict supervision decisions.

(3) The Asymptotic Stability Analysis of End Users. The first partial derivative of the replication dynamic equation with strict supervision strategy for $y$ can be obtained according to equation (12)

$$
\frac{\partial F(z)}{\partial z}=(1-2 z)\left(I_{3}+C_{5}-(1-y) P_{3}+x y \gamma S_{3}\right)
$$

If we set

$$
\Pi_{z}=\left(I_{3}+C_{5}-(1-y) P_{3}+x y \gamma S_{3}\right),
$$

and from $\Pi_{z}=0$, the following equation is yielded:

$$
\lambda_{y}=\frac{P_{3}-C_{5}-I_{3}}{P_{3}+x \gamma S_{3}} .
$$

Then, we have Conclusion 3.enun_Conclusion_3

Conclusion 3. When $\Pi_{z}>0$, the use strategy of end users is the evolutionary stability strategy; when $\Pi_{z}<0$, the nonuse strategy of end users is an evolutionary stability strategy. Moreover, the probability of $z$ increases while the probability of $x$ and $y$ increases.

Theorem 3. $\Pi_{z}=0$ is the dividing line of end users' stable state (see Figure 9(a)). Under the stability theorem of the differential equation, when $\Pi_{z}>0$ has $F_{(z)}^{\prime}(0)>0, F_{(z)}^{\prime}(1)<0$, it indicates that end users use the smart government platform in a stable state (see Figure 9(b)). Likewise, when $\Pi_{z}<0$ has $F_{(z)}^{\prime}(0)<0, F_{(z)}^{\prime}(1)>0$, it indicates that the end user does not use the strategy in a stable state, but the use strategy is unstable (see Figure 9(c)).

When $y>\lambda_{y},\left.\quad(\mathrm{~d} F(z) / \mathrm{d} z)\right|_{z=1<0}$, indicating that the evolution stable strategy of the end users is $z=1$. In other words, end users are inclined to select a use strategy when the probability of $y$ is higher than $\lambda_{y}$.

When $y<\lambda_{y},\left.\quad(\mathrm{~d} F(z) / \mathrm{d} z)\right|_{z=0<0}$, indicating that the evolution stable strategy of the end users is $z=0$. In other words, end users are inclined to select a nonuse strategy when the probability of $y$ is lower than $\lambda_{y}$. Likewise, we can prove the relationship between $x$ and $z$.

As suggested from the analysis results, for the end users, it can be seen from the formula that the use of decision $(z)$ increases with the increase in positive strategy $(x)$ of functional departments and strict supervision strategy $(y)$ of local government. The greater the comprehensive income and the total cost when not in use, the greater the credit confirmation income and privacy risk loss obtained by the user when using the blockchain technology and the higher the possibility of end users choosing the use strategy.

4.3.2. Stability Analysis of Evolution Strategy under the Action of Three Parties. Set $P(x, y, z)=(\mathrm{d} x / \mathrm{d} t)$, $G(x, y, z)=(\mathrm{d} y / \mathrm{d} t)$, and $Q(x, y, z)=(\mathrm{d} z / \mathrm{d} t)$, then equations (10)-(12) express the group dynamics of the evolution system of functional departments, local government, and end users, as written in the following equation:

$$
\left\{\begin{array}{l}
P(x, y, z)=\frac{\mathrm{d} x}{\mathrm{~d} t}=x(1-x)\left(C_{4}-C_{3}+(y-1) P_{2}+y P_{4}+y z \beta S_{2}\right), \\
G(x, y, z)=\frac{\mathrm{d} y}{\mathrm{~d} t}=y(1-y)\left(C_{2}-C_{1}+A_{1}-x A_{1}+z P_{1}+x z \alpha S_{1}\right), \\
Q(x, y, z)=\frac{\mathrm{d} z}{\mathrm{~d} t}=z(1-z)\left(I_{3}+C_{5}-(1-y) P_{3}+x y \gamma S_{3}\right) .
\end{array}\right.
$$

Set

$$
H(E)=\left\{\begin{array}{l}
P(x, y, z) \\
G(x, y, z)=0, \\
Q(x, y, z)
\end{array}\right.
$$

and there are 12 equilibrium points for the system replication dynamic equation. However, complying with the literature [44], only 8 special equilibrium points should be discussed for the replication dynamic system, as follows:

$$
\begin{aligned}
& \xi_{1}=\left(\begin{array}{l}
0 \\
0 \\
0
\end{array}\right), \\
& \xi_{2}=\left(\begin{array}{l}
1 \\
0 \\
0
\end{array}\right) \text {, } \\
& \xi_{3}=\left(\begin{array}{l}
1 \\
1 \\
0
\end{array}\right) \text {, } \\
& \xi_{4}=\left(\begin{array}{l}
1 \\
1 \\
1
\end{array}\right) \text {, } \\
& \xi_{5}=\left(\begin{array}{l}
0 \\
1 \\
0
\end{array}\right) \text {, } \\
& \xi_{6}=\left(\begin{array}{l}
0 \\
1 \\
1
\end{array}\right) \text {, } \\
& \xi_{7}=\left(\begin{array}{l}
0 \\
0 \\
1
\end{array}\right) \text {, } \\
& \xi_{8}=\left(\begin{array}{l}
1 \\
0 \\
1
\end{array}\right) \text {. }
\end{aligned}
$$

The evolutionary stability strategy (ESS) for replicating the dynamic equation system is formulated based on the local stability analysis of the Jacobian matrix of the system with the method proposed by Friedman. Moreover, the 


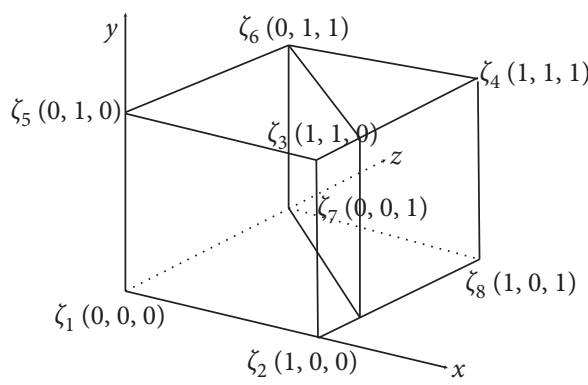

(a)

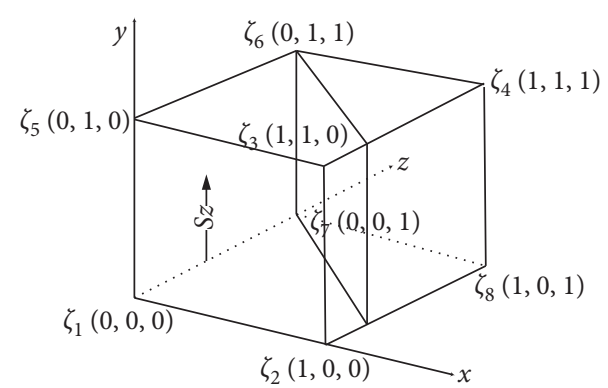

(b)

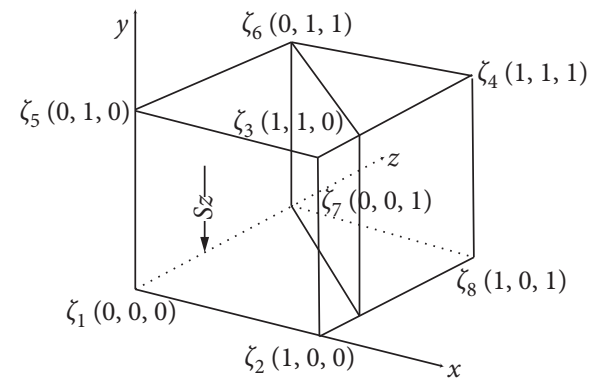

(c)

FIGURE 9: End user stability evolution phase diagram.

Jacobian matrix of the system is obtained from equation (23) as follows:

$$
J=\left[\begin{array}{ccc}
(1-2 x)\left(C_{4}-C_{3}+(y-1) P_{2}+y P_{4}+y z \beta S_{2}\right) & (1-x) x\left(P_{4}+P_{2}+z \beta S_{2}\right) & (1-x) x y \beta S_{2} \\
y(1-y)\left(z \alpha S_{1}-A_{1}\right) & (1-2 y)\left(C_{2}-C_{1}+A_{1}-x A_{1}+z P_{1}+x z \alpha S_{1}\right) & y(1-y)\left(P_{1}+x \alpha S_{1}\right) \\
z(z-1) y \gamma S_{3} & z(z-1)\left(P_{3}+x \gamma S_{3}\right) & (1-2 z)\left(I_{3}+C_{5}-(1-y) P_{3}+x y \gamma S_{3}\right)
\end{array}\right] .
$$

According to the replication dynamic equation system (13), the local equilibrium point is yielded as follows: $\xi_{1}(0,0,0), \quad \xi_{2}(1,0,0), \quad \xi_{3}(1,1,0), \quad \xi_{4}(1,1,1), \quad \xi_{5}(0,1,0)$, $\xi_{6}(0,1,1), \xi_{7}(0,0,1), \xi_{8}(1,0,1)$. By complying with Lyapunov stability theorem, when all eigenvalues $(\lambda)$ of the Jacobian matrix satisfy $\lambda<0$, the equilibrium point is the asymptotically stable. That is the confluence. When all eigenvalues of the Jacobian matrix satisfy $\lambda>0$, the equilibrium point is unstable, which is the source. Furthermore, for the Jacobian matrix, the eigenvalues $(\lambda)$ mixed states. In other words, some are positive, while others are negative. Then, the equilibrium point, also termed as the saddle point, is unstable. First, for the case where the equilibrium point is $\xi_{1}(0,0,0)$, the Jacobian matrix is as follows:

$$
J_{1}=\left[\begin{array}{ccc}
C_{4}-C_{3}-P_{2} & 0 & 0 \\
0 & C_{2}-C_{1}+A_{1} & 0 \\
0 & 0 & I_{3}+C_{5}-P_{3}
\end{array}\right]
$$

It is therefore indicated that the eigenvalues of the Jacobian matrix are $\lambda_{1}=C_{4}-C_{3}-P_{2}, \lambda_{2}=C_{2}-C_{1}+A_{1}$, and $\lambda_{3}=I_{3}+C_{5}-P_{3}$. With the identical analogy, the 8 equilibrium points are substituted into the Jacobian matrix (26), respectively, and the eigenvalues of the Jacobian matrix corresponding to the equilibrium points can be determined, respectively (Table 3 ).

According to the mentioned analysis, the evolutionary game system has stability under certain conditions. However, many parameters are accordingly involved, and the characteristic value $(\lambda)$ symbol is determined by the size of the mentioned parameter values. Under the existing known mathematical derivation method, the stability of each of the Nash equilibrium is determined, and the evolutionary game model cannot effectively lead to the reach steady state equilibrium. Accordingly, this article further employs system dynamics to analyse the impact of various uncertain factors on the evolution of the game and lays a basis for formulating relevant policies.

\section{System Dynamics Simulation Analysis}

The above paragraphs analyzed the interaction of the three subjects in the strategic choice and the influence of external variables on the stability of the evolutionary game. Though some conclusions have been drawn, they are all analyses conducted from the perspective of a single subject, lacking systematic and comprehensive analysis from the perspective of three subjects. In the 1950s, Fletcher of the Massachusetts Institute of Technology initially adopted the theory of 
TABLE 3: Eigenvalues of the Jacobian matrix.

\begin{tabular}{lccc}
\hline Equilibrium point & $\lambda_{1}$ & $\lambda_{2}$ & $\lambda_{3}$ \\
\hline$\zeta_{1}(0,0,0)$ & $C_{4}-C_{3}-P_{2}$ & $I_{3}+C_{5}-P_{3}$ \\
$\zeta_{2}(1,0,0)$ & $-\left(C_{4}-C_{3}-P_{2}\right)$ & $C_{2}-C_{1}+A_{1}$ & $I_{3}+C_{5}-P_{3}$ \\
$\zeta_{3}(1,1,0)$ & $-\left(C_{4}-C_{3}+P_{4}\right)$ & $-\left(C_{2}-C_{1}\right)$ & $I_{3}+C_{5}+\gamma S_{3}$ \\
$\zeta_{4}(1,1,1)$ & $-\left(C_{4}-C_{3}+P_{4}+\beta S_{2}\right)$ & $-\left(C_{2}-C_{1}+P_{1}+\alpha S_{1}\right)$ & $-\left(I_{3}+C_{5}+\gamma S_{3}\right)$ \\
$\zeta_{5}(0,1,0)$ & $C_{4}-C_{3}+P_{4}$ & $-\left(C_{2}-C_{1}+A_{1}\right)$ & $I_{3}+C_{5}$ \\
$\zeta_{6}(0,1,1)$ & $C_{4}-C_{3}+P_{4}+\beta S_{2}$ & $-\left(C_{2}-C_{1}+A_{1}+P_{1}\right)$ & $-\left(I_{3}+C_{5}\right)$ \\
$\zeta_{7}(0,0,1)$ & $C_{4}-C_{3}-P_{2}$ & $C_{2}-C_{1}+A_{1}+P_{1}$ & $-\left(I_{3}+C_{5}-P_{3}\right)$ \\
$\zeta_{8}(1,0,1)$ & $-\left(C_{4}-C_{3}-P_{2}\right)$ & $C_{2}-C_{1}+P_{1}+\alpha S_{1}$ & $-\left(I_{3}+C_{5}-P_{3}\right)$ \\
\hline
\end{tabular}

management science and systems science and incorporated computerized simulation technology into quantitative analyses to develop a system dynamics theory method. It is primarily adopted to study system problems with high nonlinearity, as characterized by multivariate, causal feedback, and complex time-varying.

Thus, to systematically and deeply analyse the strategic interaction between different agents, the present study uses the system dynamics theory to build a dynamic model of an intelligent government collaborative governance system based on blockchain technology, and the simulation of system dynamics with VENSIM PLE simulation software is employed to analyse the evolution of the strategic interaction.

5.1. Based on the SD Model of "Blockchain + Government Affairs Service" in Beijing. Since November 2019, Beijing Municipal Government Service Bureau, Beijing Municipal Science and Technology Commission, and Beijing Municipal Bureau of Economy and Information Technology have led the implementation of the Action Plan on the application of blockchain in the field of Government Services. The Beijing Municipal Bureau of Commerce and other departments, as the responsible units, have vigorously propelled the application construction of blockchain in government services in the four pilot areas of the city. By August 2020, 140 government affairs services have been connected in Beijing, 253 business affairs and 65 human affairs have been settled online, and 100,000 pieces of administrative materials can be simplified throughout the year. There have been 121 enterprises having used the blockchain system to query and verify various functions for nearly 7,800 times. The reported data have been down-regulated by $80 \%$, and the average material has decreased by $40 \%$.

This study combines the specific application scenarios of blockchain pilots in Haidian, Xicheng, Chaoyang, Shunyi and other blockchain pilots in the "Blue Book on the Application of Blockchain in Municipal Services in Beijing (First Edition)" issued by the Beijing Municipal Administration in July 2020. Vensim PLE software is employed to build the system dynamics model of the evolutionary game between functional departments, local governments, and end users (see Figure 10).

5.2. Initial Simulation Analysis. According to the application practice of the blockchain in the government service field of
Beijing, the initial value of the model is assumed as follows: INITIAL TIME $=0, \quad$ FINAL TIME $=20$, TIMESTEP $=0.0625$, and Units for Time: Month, and the 16 external variables are assigned as shown in Table 4 .

Since the three participating agents of functional departments, local governments, and end users have two kinds of strategy choices, 0 and 1 , this constitutes 8 strategy combinations, namely, $(0,0,0),(0,0,1),(0,1,0)$, $(1,0,0),(1,1,0),(1,0,1),(0,1,1)$, and $(1,1,1)$. When the initial states of the three parties are pure strategies, the system is in equilibrium. At this time, no one party is willing to actively change the existing strategies, and the mentioned eight strategy combinations will become the equilibrium state of the system. However, this state is not stable, as long as there is a small change in one or more subjects in the system, and the system will lose the equilibrium state. We take the combination of $(0,0,1)$ strategy as an example to illustrate, and its evolution results are shown in Figure 11(a). This figure indicates that the initial probabilities of the functional departments choosing the positive strategy and the local government choosing the strict supervision strategy are very low (both 0.01 ); in the game process, when the participants find that there are more profitable strategy choices in the system, it will adjust the original strategy, and through the continuous learning and imitating between the subjects, the system can lastly reach a novel equilibrium state.

The simulation of 8 pure strategy combinations is summarized as follows. (1) No matter the positive strategy of the functional departments starts from 0 to 0.01 or from 1 to 0.99 , and its strategy choice will eventually reach an equilibrium state at 1 . It is therefore revealed that in smart government projects, functional departments actively draw upon the smart government platform under the blockchain technology to complete the business, which is the optimal choice. Only the active use of blockchain technology to optimize the existing platform workflow can ensure its maximum revenue. (2) Under functional departments adopting positive strategies, if the local government adopts a strategy of loose supervision, no matter whether the end users change from 0 or 1 , the final strategy is 1 , i.e., $(1,0,0)$ and $(1,0,1)$. The evolution result of the two strategy combinations refers to $(1,0,1)$ (see Figure $11(b))$. If the local government carries out strict regulation, the end users will mutate from 0 or 1 , and the final strategy will be 1 , namely, $(1,1,0)$ and $(1,1,1)$. The evolution result of the two strategy combinations is $(1,1,1)$ (see Figure 11(c)). 


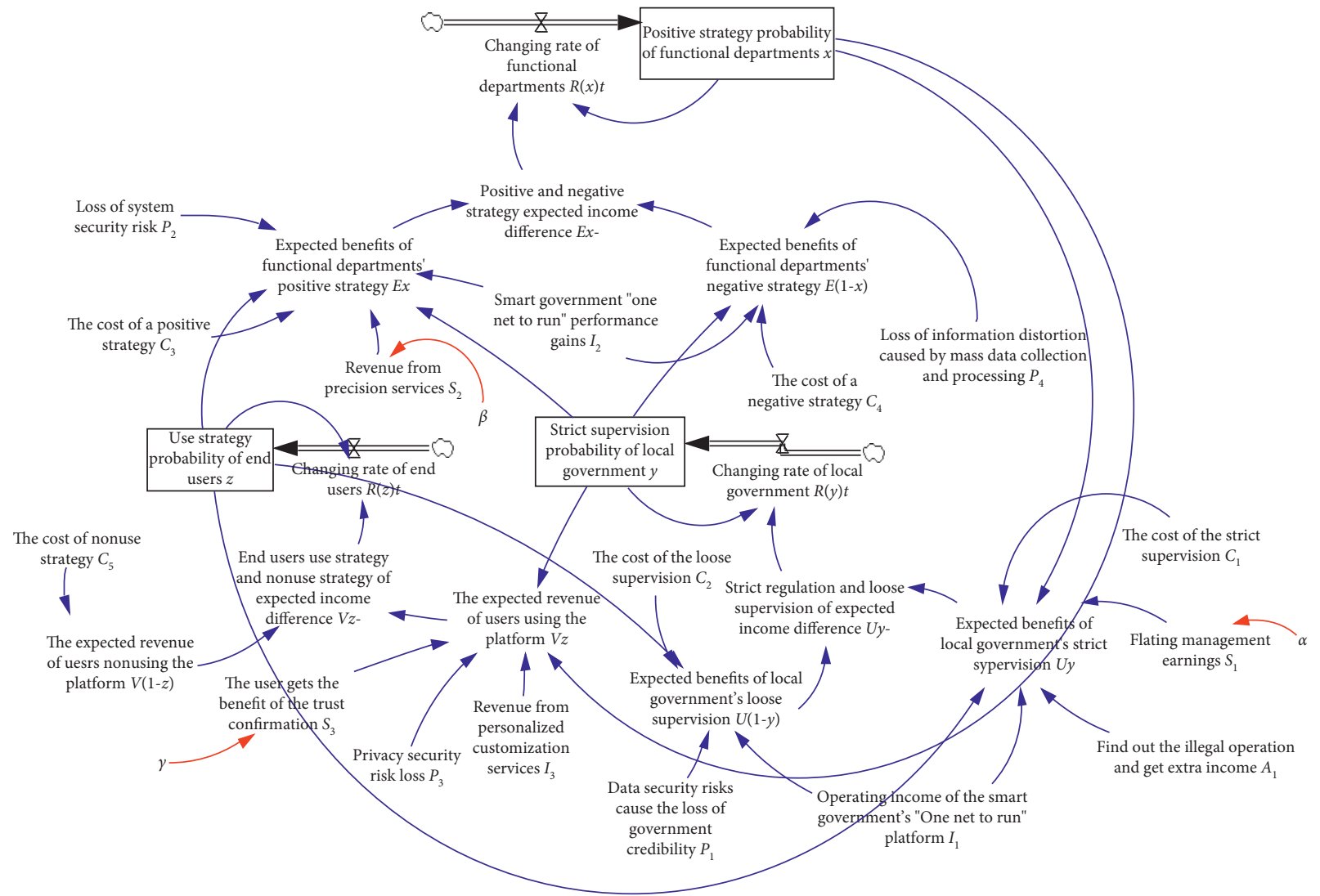

FIGURE 10: System dynamics (SD) model of functional department, local government, and end user evolutionary game system.

Moreover, it is revealed that the end users have a positive attitude towards the use of smart government affairs, and they are willing to use the platform to complete business transactions. As suggested from the analysis, through the evolutionary game process of "mutation-adjustment-equilibrium" of the three agents of the game, the system will eventually reach the equilibrium state of $(1,1,1)$.

\subsection{Simulation Analysis of the Impact of External Variables on} Strategy. Based on the above discussion, the value of each parameter determines whether each strategy combination is the equilibrium point to make the system stable state, and the impact of external variables on the strategy selection of the game subject is analysed. The following continues to take $(0,0,1)$ strategy combination as an example to discuss.

\subsubsection{Factors of Functional Departments' Strategy Choice.} In the policy combination of $(0,0,1)$, the initial state of functional departments refers to a negative strategy. It is assumed that the functional departments start from the probability of 0.01 . As indicated from the simulation, among the 16 external variables, the cost of a positive strategy $C_{3}$, the cost of a negative strategy $C_{4}$, revenue from precision services $S_{2}$, loss of system security risk $P_{2}$, loss of information distortion attributed to mass data collection and processing $P_{4}$, and the mentioned five external variables will impact the strategic choice of functional departments. In particular, accurate service degree coefficient $\beta$ should be stressed, which is the use of blockchain technology to enhance the serviceability of functional departments. By regulating the value of $\beta$, the precision income will be affected. Under other initial values unchanged, the evolution result of strategy choice probability of functional departments is analysed (see Figure 12).

As revealed from the comparison of Figures 12(b), 12(c), and $12(\mathrm{e}), C_{4}, P_{2}$, and $P_{4}$ similarly impact the evolution trend of positive strategy choice in functional departments. The higher the cost for functional departments to negatively exploit blockchain technology, the smaller the loss of system security risk when using blockchain technology, and the greater the loss of information distortion attributed to mass data collection and processing when not using blockchain technology, the more functional departments will be inclined to comply with the strategy of positively using blockchain technology. In addition, according to the simulation analysis, $C_{3}$ complexly impacts the strategy selection of functional departments. Under the extremely large $C_{3}$ value, functional departments are inclined to use blockchain technology negatively; in particular, when the value is smaller, the faster the functional departments will reach the stable state of positive strategy. It is also revealed that when functional departments positively exploit blockchain technology to complete smart government business, the cost acts as a critical factor; when the cost is too high, it will impact the choice of their strategies. 
TABLE 4: Meaning and assignment of model variables.

\begin{tabular}{|c|c|c|c|}
\hline Variable & Sign & Unit & Initial value \\
\hline Performance benefits of smart government platform business processing & $I_{2}$ & $\begin{array}{l}\text { Million } \\
\text { yuan }\end{array}$ & 10 \\
\hline Actively use blockchain technology to optimize the cost of smart government business processing & $C_{3}$ & $\begin{array}{l}\text { Million } \\
\text { yuan }\end{array}$ & 5 \\
\hline $\begin{array}{l}\text { Negative treatment of blockchain technology only maintain the cost of online business processing } \\
\text { expenditure }\end{array}$ & $C_{4}$ & $\begin{array}{l}\text { Million } \\
\text { yuan }\end{array}$ & 2 \\
\hline When not in use blockchain technology huge amounts of data collect processing information distortion & $P_{4}$ & $\begin{array}{l}\text { Million } \\
\text { yuan }\end{array}$ & 3 \\
\hline Using blockchain technology to improve the precision service level of functional departments & $\beta$ & Dmnl & 1 \\
\hline Using blockchain technology to improve the precision service revenue of functional departments & $S_{2}$ & $\begin{array}{l}\text { Million } \\
\text { yuan }\end{array}$ & 5 \\
\hline Lax supervision of local government, blockchain technology the system security risks of losses & $P_{2}$ & $\begin{array}{l}\text { Million } \\
\text { yuan }\end{array}$ & 4 \\
\hline Economic and social benefits of smart government platform operation & $I_{1}$ & $\begin{array}{l}\text { Million } \\
\text { yuan }\end{array}$ & 15 \\
\hline The cost of strict supervision & $C_{1}$ & $\begin{array}{l}\text { Million } \\
\text { yuan }\end{array}$ & 5 \\
\hline The cost of loose supervision & $C_{2}$ & $\begin{array}{l}\text { Million } \\
\text { yuan }\end{array}$ & 3 \\
\hline $\begin{array}{l}\text { When users use it, the government's lack of supervision results in privacy leakage, which damages the } \\
\text { government's credibility }\end{array}$ & $P_{1}$ & $\begin{array}{l}\text { Million } \\
\text { yuan }\end{array}$ & 6 \\
\hline $\begin{array}{l}\text { When strict supervision is carried out, the reward gains of noncompliance in functional departments are } \\
\text { found }\end{array}$ & $A_{1}$ & $\begin{array}{l}\text { Million } \\
\text { yuan }\end{array}$ & 2 \\
\hline $\begin{array}{l}\text { Blockchain technology is used to optimize the flat management efficiency of the public management } \\
\text { structure }\end{array}$ & $\alpha$ & Dmnl & 1 \\
\hline $\begin{array}{l}\text { Using blockchain technology to optimize the flat management benefits of the public management } \\
\text { structure }\end{array}$ & $S_{1}$ & $\begin{array}{l}\text { Million } \\
\text { yuan }\end{array}$ & 6 \\
\hline The net income of personalized and customized services obtained via the smart government platform & $I_{3}$ & $\begin{array}{l}\text { Million } \\
\text { yuan }\end{array}$ & 12 \\
\hline Still choose the total cost of business hall processing & $C_{5}$ & $\begin{array}{l}\text { Million } \\
\text { yuan }\end{array}$ & 8 \\
\hline $\begin{array}{l}\text { When the local government loose supervision, users will lose privacy security risks when they use the } \\
\text { platform }\end{array}$ & $P_{3}$ & $\begin{array}{l}\text { Million } \\
\text { yuan }\end{array}$ & 10 \\
\hline The degree of trust and authority that functional departments get from users using blockchain technology & $\gamma$ & Dmnl & 1 \\
\hline $\begin{array}{l}\text { Functional departments make use of the trust gained by the users of blockchain technology to determine } \\
\text { the benefits of rights }\end{array}$ & $S_{3}$ & $\begin{array}{c}\text { Million } \\
\text { yuan }\end{array}$ & 4 \\
\hline
\end{tabular}

Likewise, the precision service degree coefficient $\beta$ brought by blockchain technology to functional departments also impacts the choice of their strategies. Figure 12(e) indicates that when the degree of precision service is improved, the functional departments approach the positive strategy faster, whereas under the income of precision service reaching a certain degree, the impact on convergence turns out to be slight.

5.3.2. The Factors of Local Government Strategy Choice. As revealed from the simulation, the mentioned external variables will affect the local government's strategy choice (e.g., the cost $C_{1}$ under strict supervision, the cost $C_{2}$ under loose supervision, the incentive income $A_{1}$ under illegal operation, the credibility $P_{1}$ under data security risk loss, as well as the degree coefficient $\alpha$ of flat management) (see Figure 13). With the decrease in the value of $C_{1}$ and the increase in the values of $C_{2}, A_{1}$, and $P_{1}$, local government is more inclined to adopt a strict supervision strategy, and their evolution path displays an $S$-type growth trend. Besides, it can be seen from Figure 13(d) that when the value of $P_{1}$ is less than a certain value, the local government will eventually choose the strategy of loose supervision. As can be seen from Figure 13(c), the $A_{1}$ value is the reward income of local government for discovering illegal operations in functional departments. Accordingly, the strategy selection of local governments is influenced by functional departments. Local governments play a normative and guiding role in the behaviour of functional departments. An appropriate increase in $A_{1}$ value can promote local governments to choose a strict supervision strategy. The value of $P_{1}$ is the public credibility compromised by the data security risk. When loose supervise undermines credibility, local government is emboldened to go slow. When the credibility of the damaged government is high, the local government has a sense of 




Positive strategy probability of functional departments $x$ :

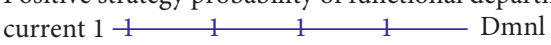

Strict supervision probability of local government $y$ : current $1 \begin{array}{lllll}2 & 2 & 2 & 2 & \text { Dmnl }\end{array}$

Use strategy probability of end users $z$ :

current $1 \begin{array}{lllllll}3 & 3 & 3 & 3 & 3 & 3\end{array}$

(a)

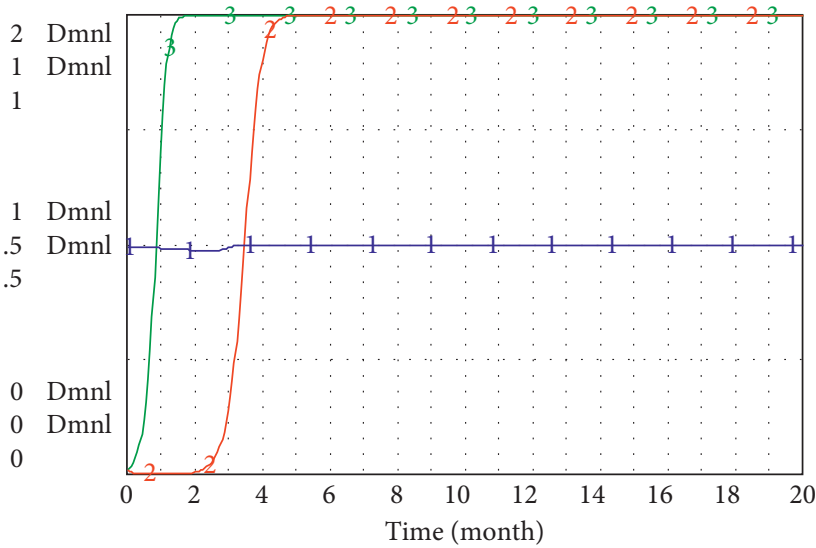

Positive strategy probability of functional departments $x$ : $\begin{array}{llllll}\text { current } 1 & 1 & 1 & 1 & 1 & 1\end{array}$

Strict supervision probability of local government $y$ : current $1-\begin{array}{llll}2 & 2 & 2 & 2\end{array}$

Use strategy probability of end users $z$ : current 1

(b)



Positive strategy probability of functional departments $x$ : current $1+1 \quad \begin{array}{llll}1 & 1 & 1 & 1\end{array}$

Strict supervision probability of local government $y$ : current $1-\begin{array}{lllll}2 & 2 & 2 & 2 & \text { Dmnl }\end{array}$

Use strategy probability of end users $z$ : current $1 \begin{array}{lllllll} & 3 & 3 & 3 & 3 & 3 & 3\end{array}$

(c)

FiguRE 11: Evolutionary results for different values of $x, y$, and $z$ : (a) $x=0.01, y=0.01$, and $z=1$; (b) $x=1, y=0.01$, and $z=0.01$; (c) $x=1, y=1$, and $z=0.99$.

crisis. To maintain their good image, they must strictly supervise and ensure the reputation of the government. Likewise, Figure 13(e) indicates that when the value $\alpha$ is the local government's strict supervision, the higher the ratio of the flat public management efficiency, the faster the local government's strict supervision strategy will approach to 1 . However, when the ratio of the flat public management efficiency reaches a certain degree, the impact on the convergence is not so obvious.
5.3.3. The Factors of the End Users' Strategy Choice. Given the simulation analysis results, the variables (e.g., the benefits of personalized service received by the end user via the smart government platform $I_{3}$, the cost of going to the hall for business $C_{5}$, the loss of user privacy and security risk $P_{3}$, and the coefficient of users' trust confirmation) significantly impact the user strategy choice (see Figure 14). Figures 14(a) and 14(b) indicate that when users draw upon the smart government platform for business, the greater the 
Positive strategy probability of functional departments $x$



Positive strategy probability of functional departments $x$ $\begin{array}{lllllll}\text { : current } 1 & 1 & 1 & 1 & 1 & 1 & 1\end{array}$

Positive strategy probability of functional departments $x$ : current $2 \begin{array}{llllll}2 & 2 & 2 & 2 & 2 & 2\end{array}$

Positive strategy probability of functional departments $x$ : current $3 \begin{array}{llllllll}3 & 3 & 3 & 3 & 3 & 3 & 3\end{array}$

(a)

Positive strategy probability of functional departments $x$

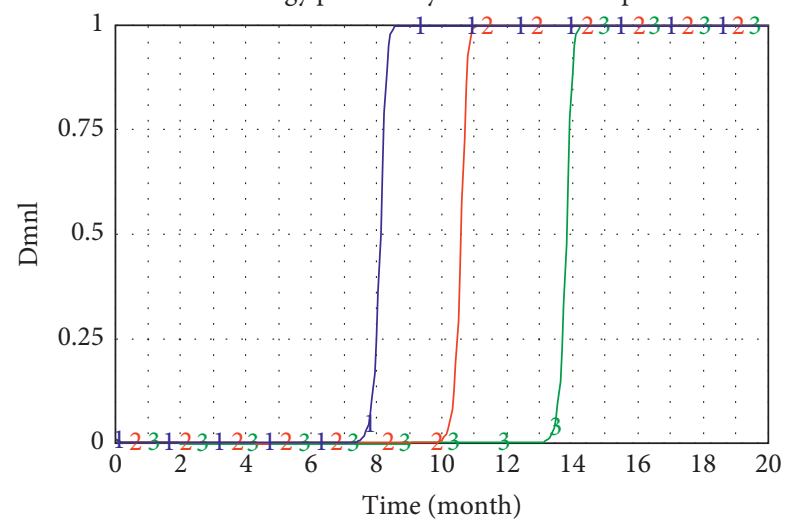

Positive strategy probability of functional departments $x$ $\begin{array}{lllllll}\text { : current } 1 & 1 & 1 & 1 & 1 & 1 & 1\end{array}$

Positive strategy probability of functional departments $x$ : current $2 \begin{array}{llllll}2 & 2 & 2 & 2 & 2 & 2\end{array}$

Positive strategy probability of functional departments $x$ : current $3 \begin{array}{llllllll}3 & 3 & 3 & 3 & 3 & 3 & 3\end{array}$

(c)
Positive strategy probability of functional departments $x$

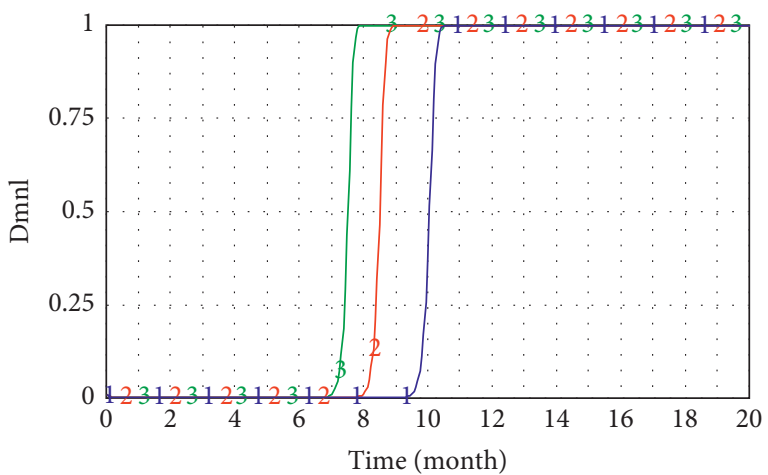

Positive strategy probability of functional departments $x$ $\begin{array}{lllllllllll}\text { : current } 1 & 1 & 1 & 1 & 1 & 1 & 1\end{array}$

Positive strategy probability of functional departments $x$ : current $2 \begin{array}{llllll}2 & 2 & 2 & 2 & 2 & 2\end{array}$

Positive strategy probability of functional departments $x$ : current $3 \begin{array}{llllllll}3 & 3 & 3 & 3 & 3 & 3 & 3\end{array}$

(b)

Positive strategy probability of functional departments $x$



Positive strategy probability of functional departments $x$ $\begin{array}{lllllll}\text { : current } 1 & 1 & 1 & 1 & 1 & 1 & 1\end{array}$

Positive strategy probability of functional departments $x$ : current $2 \begin{array}{llllll}2 & 2 & 2 & 2 & 2 & 2\end{array}$

Positive strategy probability of functional departments $x$ : current $3 \begin{array}{llllllll}3 & 3 & 3 & 3 & 3 & 3 & 3\end{array}$

(d)

FIgURE 12: Continued. 


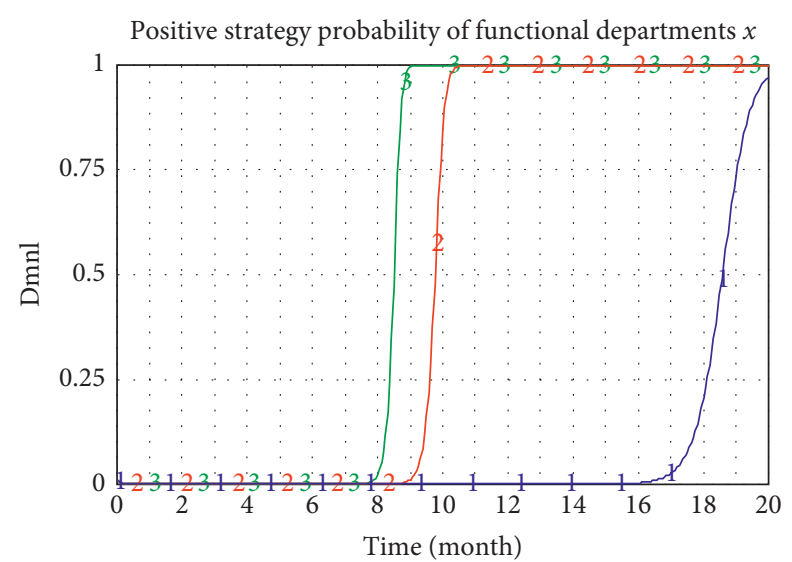

Positive strategy probability of functional departments $x$ $\begin{array}{lllllll}\text { : current } 1 & 1 & 1 & 1 & 1 & 1 & 1\end{array}$

Positive strategy probability of functional departments $x$ : current $2 \begin{array}{llllll}2 & 2 & 2 & 2 & 2 & 2\end{array}$

Positive strategy probability of functional departments $x$ : current $3 \begin{array}{llllllll}3 & 3 & 3 & 3 & 3 & 3 & 3\end{array}$

(e)

Figure 12: The impact of external variables on the strategic choice of functional departments: (a) Current $1: C_{3}=4$, Current $2: C_{3}=6$, and Current 3: $C_{3}=8$; (b) Current 1: $C_{4}=2$, Current 2: $C_{4}=3$, and Current 3: $C_{4}=4$; (c) Current $1: P_{2}=2$, Current 2: $P_{2}=5$, and Current 3: $P_{2}=8$; (d) Current 1: $P_{4}=3$, Current $2: P_{4}=5$, and Current $3: P_{4}=7$; (e) Current $1: \beta=0.1$, Current $2: \beta=0.4$, and Current $3: \beta=0.9$.

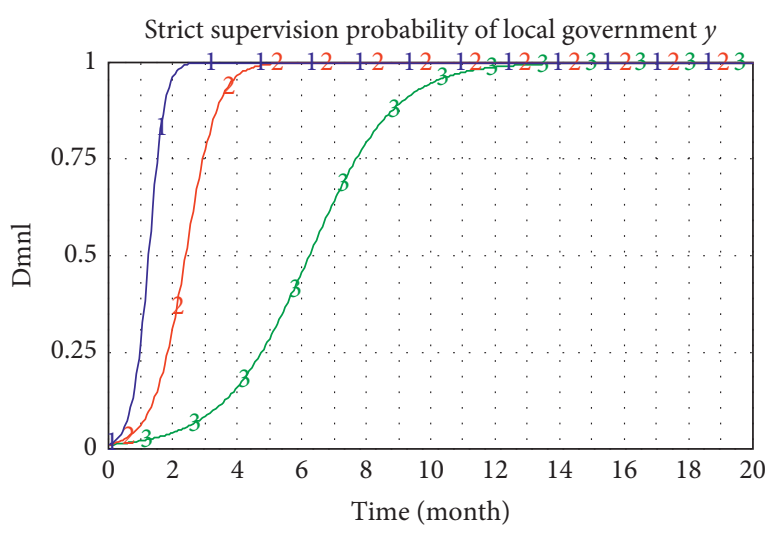

Strict supervision probability of local government $y$

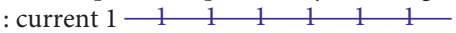

Strict supervision probability of local government $y$ : current $2 \begin{array}{llllll}2 & 2 & 2 & 2 & 2 & 2\end{array}$

Strict supervision probability of local government $y$ : current $3 \begin{array}{lllllll}3 & 3 & 3 & 3 & 3 & 3 & 3\end{array}$

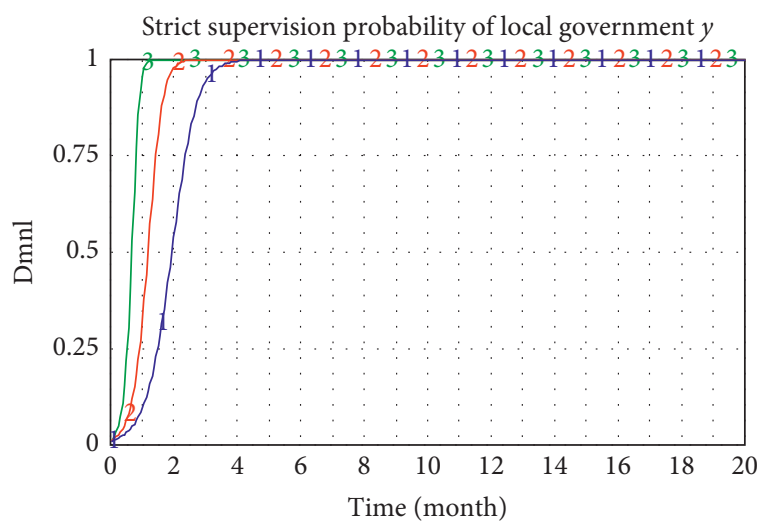

Strict supervision probability of local government $y$ $\begin{array}{lllllll}\text { : current } 1 & 1 & 1 & 1 & 1 & 1 & 1\end{array}$

Strict supervision probability of local government $y$ : current $2 \begin{array}{llllll}2 & 2 & 2 & 2 & 2\end{array}$

Strict supervision probability of local government $y$ : current $3 \begin{array}{lllllll}3 & 3 & 3 & 3 & 3 & 3 & 3\end{array}$

(a)

FIgURE 13: Continued. 


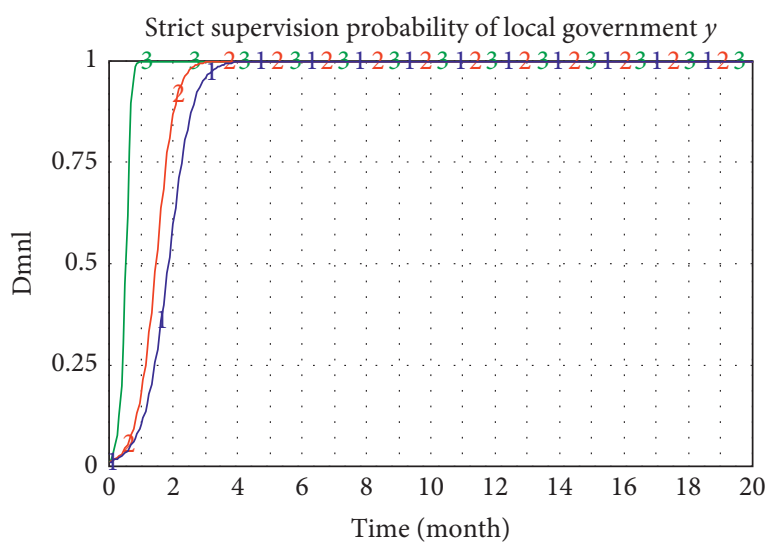

Strict supervision probability of local government $y$

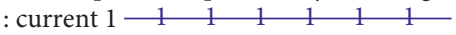

Strict supervision probability of local government $y$ : current $2 \begin{array}{llllll}2 & 2 & 2 & 2 & 2 & 2\end{array}$

Strict supervision probability of local government $y$ : current $3 \begin{array}{lllllll}3 & 3 & 3 & 3 & 3 & 3 & 3\end{array}$

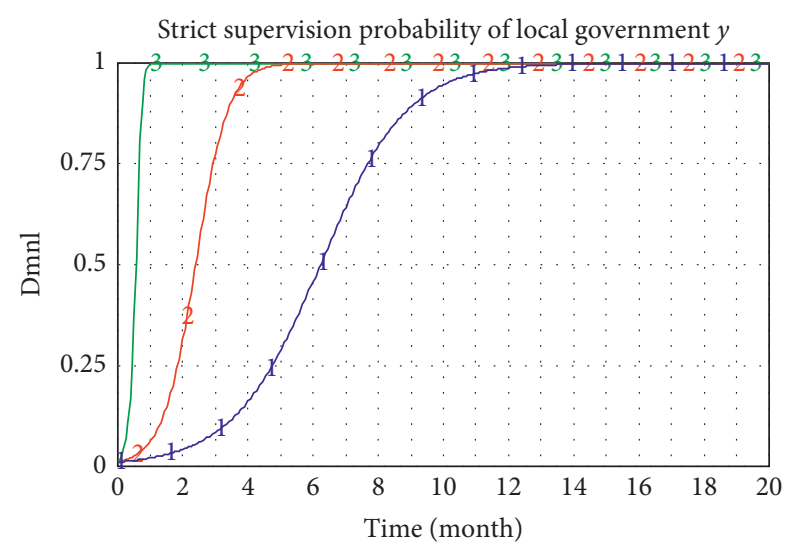

Strict supervision probability of local government $y$ : current $1-1 \quad \begin{array}{lllllll}1 & 1 & 1 & 1 & 1 & 1\end{array}$

Strict supervision probability of local government $y$ : current $2 \quad \begin{array}{llllll}2 & 2 & 2 & 2 & 2 & 2\end{array}$

Strict supervision probability of local government $y$

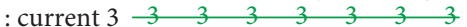

(d)

(c)



Strict supervision probability of local government $y$

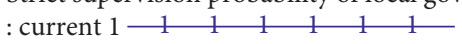

Strict supervision probability of local government $y$ : current $2 \begin{array}{llllll}2 & 2 & 2 & 2 & 2 & 2\end{array}$

Strict supervision probability of local government $y$ : current $3 \begin{array}{llllllll}3 & 3 & 3 & 3 & 3 & 3 & 3\end{array}$

(e)

Figure 13: The impact of external variables on the strategic choice of local government: (a) Current $1: C_{1}=5$, Current $2: C_{1}=7$, and Current 3: $C_{1}=9$; (b) Current 1: $C_{2}=3$, Current 2: $C_{2}=5$, and Current $3: C_{2}=7 ;$ (c) Current $1 A_{1}=2$, Current 2: $A_{1}=4$, and Current 3: $A_{1}==6$; (d) Current $1: P_{1}=4$, Current $2: P_{1}=7$, and Current $3: P_{1}=10$; (e) Current $1: \alpha=0.1$, Current $2: \alpha=0.4$, and Current $3: \alpha=0.9$.

revenue and the higher the cost of business without using the platform, the more likely they will be to comply with the use strategy. According to Figure 14(c), when the local government is lax in supervision and the users cause the loss of privacy security risk of the smart government platform to be higher than a certain value, the users' profit from using the platform will be damaged, and the users are inclined to choose to still go to the service hall to handle business. It is therefore suggested that the strategy choice of users displays a tight association with the supervision intensity of local governments. Figure 14(d) suggests that the trust mechanism of blockchain technology mentioned in extensive studies had slight effects on the choice of smart government platform with blockchain technology in this study model. This may be explained as the trust mechanism under blockchain technology is a trust completely based on machine and logic. Users do not have intuitive feelings when using, so it slightly impacts users' decision-making behaviour. 




Use strategy probability of end users $z$

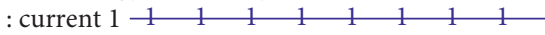

Use strategy probability of end users $z$ : current $2 \begin{array}{lllllllll}2 & 2 & 2 & 2 & 2 & 2 & 2 & 2 & 2\end{array}$

Use strategy probability of end users $z$



(a)

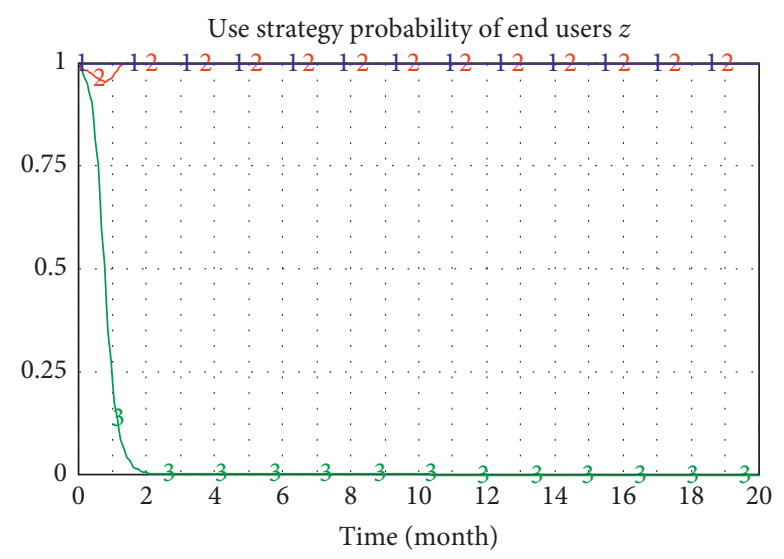

Use strategy probability of end users $z$

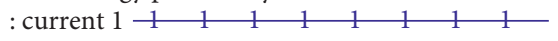

Use strategy probability of end users $z$



Use strategy probability of end users $z$

: current $3 \begin{array}{lllllllll}3 & 3 & 3 & 3 & 3 & 3 & 3 & 3\end{array}$

(c)

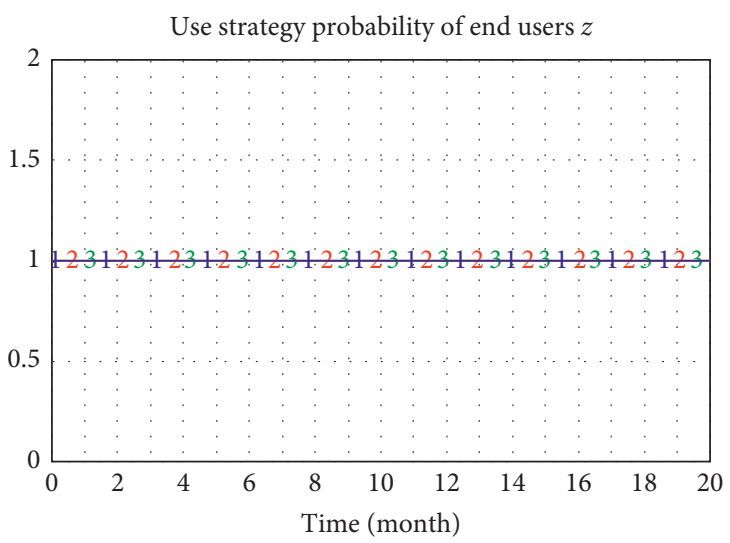

Use strategy probability of end users $z$



Use strategy probability of end users $z$

: current $2 \begin{array}{lllllllll}2 & 2 & 2 & 2 & 2 & 2 & 2 & 2 & 2\end{array}$

Use strategy probability of end users $z$



(b)



Use strategy probability of end users $z$

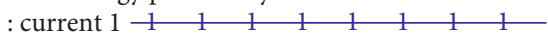

Use strategy probability of end users $z$

: current $2 \begin{array}{llllllll}2 & 2 & 2 & 2 & 2 & 2 & 2 & 2\end{array}$

Use strategy probability of end users $z$

$\begin{array}{lllllllll}: \text { current } 3 & 3 & 3 & 3 & 3 & 3 & 3 & 3 & 3\end{array}$

(d)

Figure 14: The impact of external variables on the end user's strategy choice: (a) Current $1: I_{3}=5$, Current $2: I_{3}=7$, and Current $3: I_{3}=10$; (b) Current 1: $C_{5}=8$, Current 2: $C_{5}=10$, and Current 3: $C_{5}=12$; (c) Current $1 P_{3}=10$, Current $2: P_{3}=14$, and Current $3: P 3=18 ;(d)$ Current $1: \gamma=0.1$, Current $2: \gamma=0.4$, and Current $3: \gamma=0.9$.

\section{Conclusions}

Compared with the existing online government affairs operation model, the smart government affairs collaborative governance model with blockchain technology is conducive to building a data credibility mechanism and solving the problems of trust uncertainty, nontampering, and traceability, while effectively mobilizing the enthusiasm of multiple participation in governance, forging a novel situation of collaborative governance of multiple subjects, and achieving the cooperation mode of "government-led, market operation, and multiple participation." With evolutionary game theory to analyse the cooperation strategies of functional departments, local governments, and end users in the smart government collaborative governance model with blockchain technology, it is found that the change of the general equilibrium point (saddle point) impacts the change of game evolution characteristics and the stability analysis of the evolutionary game. Based on evolutionary game stability analysis and system dynamics simulation results, the primary conclusions and limitations are as follows.

First, cost control of collaborative governance is the primary issue in a blockchain technology smart government system. For 
instance, the cost of functional departments participating in the work of building trusted infrastructure and common underlying blockchain platforms, as well as the cost of local government business regulation and technical supervision. On the whole, they impact the stability of the decision-making behaviour of the participants in collaborative governance.

Second, information security is a determining factor in advancing the widespread use of the blockchain smart government system. As indicated from the simulation, when the immaturity of blockchain technology increases the potential threat to the information security of the original system replacement, this function will reduce the comprehensive income of the smart government system, so functional departments will not use blockchain technology. Likewise, when end users use a smart government system that elevates the risk of private information leakage, they will refuse to use the system and prefer spending more time going to the lobby to conduct business.

Lastly, the "decentralized" structure and "precision" mechanism of blockchain technology can indeed elevate the level of precision service of functional departments and the flat management capability of local governments. However, according to Figures 12(e) and 13(e) of the simulation, with the coefficient rising to a certain level, the effect on decision-making behaviour is slight. However, the impact of blockchain technology's "detrust" architecture on the system is relatively weak, as seen in simulation Figure 14(d), where the increase in trust factor for end users only changes the smoothness of the decision curve, whereas it does not affect users' decision-making behaviour. This indicates that in the short term, the increase in trust level does not noticeably impact the collaborative governance system.

Though the research in the present study has certain practical significance and practical value, there are still limitations and shortcomings. First, the selection of Beijing "blockchain + government service" case has its particularity, so the expansion income is insufficient. Second, based on the change of external variable assignment to determine the strategy selection effect, only using case simulation, practical application should be combined with the concrete situation which further analysis validation. Lastly, the development of blockchain technology remains preliminary, and the publicity and nonprofit nature of government services determine that its role in the governance process is subject to certain limitations, requiring in-depth explorations. Thus, further deepening the model in combination with the reality and more appropriate simulation and optimization of the smart government collaborative governance model with blockchain technology are the direction of future research.

\section{Data Availability}

The data used to support the findings of this study are available from the corresponding author upon request.

\section{Conflicts of Interest}

The authors declare that they have no conflicts of interest.

\section{Acknowledgments}

This research was funded by the Scientific Research Foundation of the Education Department of Liaoning Province grant number 202001.

\section{References}

[1] http://www.ibm.com/smarterplanet/cn/zh/government/nextsteps/ index.html?re=sphAvailable online: 2011 (accessed on December 2008.

[2] Available online: https://publicadministration.un.org/egovkb/ Portals/egovkb/Documents/un/2018-Survey/E-Government\% 20Survey\%202018_FINAL\%20for\%20web.pdf (accessed on 19 July 2018).

[3] M. M. Kamal, V. Weerakkody, and S. Jones, "The case of EAI in facilitating e-Government services in a Welsh authority," International Journal of Information Management, vol. 29, no. 2, pp. 161-165, 2009.

[4] A. Mishra and D. Mishra, "E-government - exploring the different dimensions of challenges, implementation, and success factors," Data Base For Advances in Information Systems, vol. 42, no. 4, pp. 23-37, 2011.

[5] A. Groznik and P. Trkman, "Upstream supply chain management in e-government: the case of Slovenia," Government Information Quarterly, Government Information Quarterly, vol. 26, no. 3, pp. 459-467, 2009.

[6] Available online: https://difang.gmw.cn/gz/2019-05/27/ content_32870708.htm (accessed on May 2019).

[7] S. M. Wu, D. Q. Guo, and Y. J. Wu, "Future development of taiwan's smart cities from an information security perspective," Sustainability, vol. 10, no. 12, 4520 pages, 2018.

[8] D. Garcia, "Leaking privacy and shadow profiles in online social networks," Science Advances, vol. 3, Article ID e1701172, 2017.

[9] E. A. Miller and V. Mor, "Balancing regulatory controls and incentives: toward smarter and more transparent oversight in long-term care," Journal of Health Politics Policy and Law, vol. 33, no. 2, pp. 249-279, 2008.

[10] X. J. Kong, X. T. Liu, and B. Jedari, "Mobile crowdsourcing in smart cities: technologies, applications, and future challenges," IEEE Internet of Things Journal, vol. 6, no. 5, pp. 8095-8113, 2019.

[11] H. Yu, Z. Yang, and R. O. Sinnott, "Decentralized big data auditing for smart city environments leveraging blockchain technology," IEEE Access, vol. 7, pp. 6288-6296, 2019.

[12] M. Sun and J. Zhang, "Research on the application of block chain big data platform in the construction of new smart city for low carbon emission and green environment," Computer Communications, vol. 149, pp. 332-342, 2020.

[13] A. Ferraris, G. Santoro, and A. C. Pellicelli, "Openness'of public governments in smart cities: removing the barriers for innovation and entrepreneurship," International Entrepreneurship and Management Journal, vol. 16, pp. 1259-1280, 2020.

[14] H. Yeh, "The effects of successful ICT-based smart city services: from citizens' perspectives," Government Information Quarterly, Government Information Quarterly, vol. 34, no. 3, pp. 556-565, 2017.

[15] X. Z. Zhao and G. Wenyao, "How does local government innovation keep sustainable: an organizational approach base on a concept of "security zone for achievements"-a case study of smart city project in $\mathrm{H}$ city," Journal of Public Management, 2020. 
[16] N. Z. Sheng, F. Li, and X. F. Li, "Data capitalization method based on blockchain smart contract for internet of things," Journal of Zhejiang University. Engineering Science, vol. 11, pp. 2150-2158, 2018.

[17] B. Otjacques, P. Hitzelberger, and F. Feltz, "Interoperability of E-government information systems: issues of identification and data sharing," Journal of Management Information Systems, vol. 23 , no. 4 , pp. $29-51,2007$.

[18] Available online: http://www.wetorcem.org/reports/deep-shifttechnology-tipping-points-and-societal-impeat (accessed on September 2015).

[19] Q. Wang, M. Su, and R. Li, "Is China the world's blockchain leader? Evidence, evolution and outlook of China's blockchain research," Journal of Cleaner Production, vol. 264, Article ID 121742, 2020.

[20] X. S. Li and Y. L. Ding, "Holistic governance for sustainable public services: reshaping government-enterprise relationships in China's digital government context," International Journal of Environmental Research and Public Health, vol. 17, no. 5, 1178 pages, 2020.

[21] S. Olnes, "Beyond bitcoin enabling smart government using blockchain technology," Electronic Government, vol. 9820, pp. 253-264, 2019.

[22] J. A. T. Casallas, J. M. C. Lovelle, and J. I. R. Molano, "Smart contracts with blockchain in the public sector," International Journal of Interactive Multimedia and Artificial Intelligence, vol. 6, pp. 63-72, 2020.

[23] V. Y. Fantis, H. C. Leligou, and K. Ntalianis, "New development: blockchain-a revolutionary tool for the public sector," Public Money \& Management, vol. 9, pp. 63-72, 2020.

[24] S. Myeong and Y. Jung, "Administrative reforms in the fourth industrial revolution: the case of blockchain use," Sustainability, vol. 11, p. 3971, 2019.

[25] G. Tshering and S. Gao, "Understanding security in the government's use of blockchain technology with value focused thinking approach," Journal of Enterprise Information Management, vol. 33, no. 3, pp. 519-540, 2020.

[26] C. Sullivan and E. Burger, "E-residency and blockchain," Computer Law \& Security Review, vol. 33, no. 4, pp. 470-481, 2017.

[27] Y. G. Fu and J. M. Zhu, "Operation mechanism for G2B system based on blockchain," Tehnickivjesnik-Technical Gazette, vol. 26, no. 6, pp. 1841-1852, 2019.

[28] P. Paech, "The governance of blockchain financial networks," The Modern Law Review, vol. 80, no. 6, pp. 1073-1110, 2017.

[29] I. J. Orji, S. Kusi-Sarpong, S. F. Huang, and D. Vazquez-Brust, "Evaluating the factors that influence blockchain adoption in the freight logistics industry," Transportation Research Part E-Logistics and Transportation Review, vol. 141, Article ID 102025, 2020.

[30] H. Albayati, S. K. Kim, and J. J. Rho, “Accepting financial transactions using blockchain technology and cryptocurrency: a customer perspective approach," Technology in Society, vol. 62, 2020.

[31] E. Pournaras, "Proof of witness presence: blockchain consensus for augmented democracy in smart cities," Journal of Parallel and Distributed Computing, vol. 145, pp. 160-175, 2020.

[32] E. B. Sifah, H. Xia, C. N. A. Cobblah, Q. Xia, J. Gao, and X. Du, "BEMPAS: a decentralized employee performance assessment system based on blockchain for smart city governance," IEEE Access, vol. 8, pp. 99528-99539, 2020.

[33] L. Kallstrom, S. Mauro, A. Sancino, and G. Grossi, "The governance games of citizens and stakeholders' engagement: longitudinal narratives," Local Government Studies, vol. 8, 2020.

[34] X. Wang, Q. L. He, and Q. Ji, "Evolutionary dynamics of consumers' crowdfunding strategies based on replicator dynamics," System Engineering Theory and Practice, vol. 37, pp. 2812-2820, 2017.

[35] J. Ju, L. Liu, and Y. Feng, "Design of an $\mathrm{O}_{2} \mathrm{O}$ citizen participation ecosystem for sustainable governance," Information Systems Frontiers, vol. 21, no. 3, pp. 605-620, 2019.

[36] N. Zhang, X. X. Zhang, and M. Lei, "Multiagent collaborative governance for targeted poverty alleviation from the perspective of stakeholders," Complexity, vol. 2020, Article ID 8276392, 21 pages, 2020.

[37] M. Zhang, H. Li, and Y. Song, "Study on the heterogeneous government synergistic governance game of haze in China," Journal of Environmental Management, vol. 248, Article ID 109318, 2019.

[38] S. T. Xu, Z. F. Zhou, and K. Liu, "Multi-evolutionary game research on heavy metal pollution control in soil: based on a third-party perspective," Sustainability, vol. 12, no. 13, p. 5306, 2020.

[39] Y. X. Chen, J. Zhang, and P. R. Tadikamalla, “The relationship among government, enterprise, and public in environmental governance from the perspective of multi-player evolutionary game," International Journal of Environmental Research and Public Health, vol. 16, no. 18, p. 3351, 2019.

[40] X. L. Wan and X. Q. Qie, "Poverty alleviation ecosystem evolutionary game on smart supply chain platform under the government financial platform incentive mechanism," Journal of Computational and Applied Mathematics, vol. 372, Article ID 112595, 2020.

[41] J. Hou and B. Z. Li, "The evolutionary game for collaborative innovation of the IoT industry under government leadership in China: an IoT infrastructure perspective," Sustainability, vol. 12, 2020.

[42] Z. Lv, X. Li, W. Wang, B. Zhang, J. Hu, and S. Feng, "Government affairs service platform for smart city," Future Generation Computer Systems, vol. 81, pp. 443-451, 2018.

[43] G. V. Pereira, M. A. Cunha, and T. J. Lampoltshammer, "Increasing collaboration and participation in smart city governance: a cross-case analysis of smart city initiatives," Information Technology for Development, vol. 23, no. SI, pp. 526-553, 2017.

[44] X. P. Li, H. B. Wang, G. Hao, and C. Y. Xia, "The mechanism of alliance promotes cooperation in the spatial multi-games," Physics Letters A, vol. 384, no. 20, Article ID 126414, 2020. 